\title{
Neuron-Glia Interactions in Neural Plasticity: Contributions of Neural Extracellular Matrix and Perineuronal Nets
}

\author{
Egor Dzyubenko, ${ }^{1,2}$ Christine Gottschling, ${ }^{1}$ and Andreas Faissner ${ }^{1}$ \\ ${ }^{1}$ Department of Cell Morphology and Molecular Neurobiology, Faculty of Biology and Biotechnology, Ruhr-University, \\ Universitätsstraße 150, 44801 Bochum, Germany \\ ${ }^{2}$ International Graduate School of Neuroscience, Building FNO 01/114, Ruhr-University, Universitätsstraße 150, \\ 44801 Bochum, Germany
}

Correspondence should be addressed to Andreas Faissner; andreas.faissner@ruhr-uni-bochum.de

Received 11 June 2015; Accepted 10 August 2015

Academic Editor: Daniela Carulli

Copyright (C) 2016 Egor Dzyubenko et al. This is an open access article distributed under the Creative Commons Attribution License, which permits unrestricted use, distribution, and reproduction in any medium, provided the original work is properly cited.

\begin{abstract}
Synapses are specialized structures that mediate rapid and efficient signal transmission between neurons and are surrounded by glial cells. Astrocytes develop an intimate association with synapses in the central nervous system (CNS) and contribute to the regulation of ion and neurotransmitter concentrations. Together with neurons, they shape intercellular space to provide a stable milieu for neuronal activity. Extracellular matrix (ECM) components are synthesized by both neurons and astrocytes and play an important role in the formation, maintenance, and function of synapses in the CNS. The components of the ECM have been detected near glial processes, which abut onto the CNS synaptic unit, where they are part of the specialized macromolecular assemblies, termed perineuronal nets (PNNs). PNNs have originally been discovered by Golgi and represent a molecular scaffold deposited in the interface between the astrocyte and subsets of neurons in the vicinity of the synapse. Recent reports strongly suggest that PNNs are tightly involved in the regulation of synaptic plasticity. Moreover, several studies have implicated PNNs and the neural ECM in neuropsychiatric diseases. Here, we highlight current concepts relating to neural ECM and PNNs and describe an in vitro approach that allows for the investigation of ECM functions for synaptogenesis.
\end{abstract}

\section{Introduction}

The development of the mammalian brain unfolds in a sequence of precisely orchestrated steps. After neurogenesis and gliogenesis neurons have migrated to their final destinations. Thereafter, the process of axon growth and guidance generates a complex network of connections that is crucial for correct central nervous system (CNS) function. Axons terminate in synapses that mediate the transfer and the storage of information. The synapse thus represents the central functional element of the nervous system. It consists of a presynapse, the synaptic cleft, and the postsynaptic membrane [1-3]. This functional unit is formed during development of the nervous system and is subject to malleability in the adult nervous system $[3,4]$. There, modifications of synaptic connections on the functional and the structural level are believed to underlie synaptic plasticity that plays a key role in the context of learning and memory [3]. A whole range of cell adhesion molecules are involved in synapse formation and maturation [5]. Synaptic machinery is an intricately organized mechanism where transmembrane proteins work in concert with pre- and postsynaptic factors including cytokines $[2,6]$, Eph-kinases and ephrin ligands [7], cell adhesion molecules [8-11], neurexins and neuroligins [12], extracellular matrix (ECM) glycoproteins [13, 14], complementary integrin receptors [15], Narp/NP2, wnt7A, and FGF22 $[3,16]$, and several intracellular scaffolding molecules that anchor postsynaptic receptors $[1,17,18]$. The role of guidance molecules in synapse formation and plasticity was previously reviewed [19], and in this paper we will focus on the role of ECM in neural plasticity.

ECM provides a highly organized environment that mediates a broad spectrum of intercellular interaction in the CNS. In a subpopulation of neurons ECM develops into a specific formation termed perineuronal nets $[20,21]$. Perineuronal nets (PNNs) were described by Camillo Golgi as 
a honeycomb-like precipitate around a subpopulation of silver-stained neurons [22]. The latter includes fast spiking GABAergic interneurons expressing parvalbumin [23, 24], and sometimes other types of neurons, for example, excitatory pyramidal neurons, can exhibit these macromolecular structures $[25,26]$. PNNs localize to the soma and dendrites and delineate synapses on neuronal surfaces, which led to the hypothesis that PNNs contribute to the regulation of neuronal plasticity $[22,27]$. Their function is based on the net-like assembly of ECM components that are heterogeneously expressed $[28,29]$ and interact with the pericellular microenvironment and the surrounding cells. Both neurons and astrocytes contribute to the formation of the tripartite synapse [30]. In the past years, numerous studies have been published examining the structure and function of PNNs in the central nervous system. Within the present review, we will focus on our approach to study the neural ECM in PNNs in the context of astrocyte-neuron interactions and their regulatory function in the establishment of synaptic connections and their maintenance and plasticity.

\section{ECM of the CNS}

The ECM is composed of glycoproteins and proteoglycans that form an interactive network of macromolecules for which the term matrisome has been proposed [20, 21]. According to this description, the matrisome core comprises about 300 genes whose products structure the extracellular space and function as a scaffold for the binding of various molecular ligands and cells. While it had originally been thought that the ECM of the CNS is confined to the basal lamina of blood vessels and the meninges, a wealth of data has meanwhile shown that it plays crucial roles in the neural stem cell compartment [31,32], in axon growth and guidance [33], in the visual system [34], and in the lesion response of the CNS [35-37]. The ECM of the CNS consists of glycoproteins including laminins, tenascins, thrombospondins $[33,38]$, and proteoglycans. The latter ones comprise a core protein and at least one covalently linked unbranched glycosaminoglycan (GAG) chain, which defines the subtypes of heparan sulfate proteoglycans (HSPGs) [39-42] and chondroitin sulfate proteoglycans (CSPGs) [43-45]. In particular CSPGs of the lectican family such as aggrecan [46-54], brevican [55-59], neurocan $[46,55,60-62]$, and versican $[46,55,61,63,64]$ (for a detailed review concerning lecticans see [65]) are abundantly expressed in the developing CNS and enriched in (PNN) structures [66]. These are thought to be involved in processes such as ion-buffering [67], connection to the intracellular cytoskeleton [22], protection against oxidative stress [68], and stabilization of synapses [69] (see below). With the exception of one splice variant of brevican that is anchored to the plasma membrane via GPI [59], all members of the lectican family are secreted into the extracellular space [45].

\section{PNNs Composition and Structure}

In close proximity to certain types of CNS neurons, the diffuse distribution of ECM changes towards a highly condensed configuration, creating a specific formation termed PNNs $[20,21]$. These assemblies are identified as the areas of dense immunocytochemical staining for one of their core molecular components. The most widely used markers to detect PNNs include Wisteria floribunda agglutinin (WFA) lectin and antibodies against CSPG core proteins [24, 70, 71]. Although the expression of PNNs components displays some heterogeneity throughout different brain regions [29, 72], several of them can be defined as core components [66, 73]. In particular, the CSPGs of the lectican family [28] are highly enriched in PNNs and share a conserved globular domain at their N-terminus whereby they interact with hyaluronic acid (HA) [49, 55, 65, 74-76], another core component of PNNs (Figure 1). The HA is composed of disaccharides consisting of $\mathrm{N}$-acetylglucosamine and glucuronic acid that forms a linear structured polymer [36, 77] which is not bound to a core protein [36, 78-80]. According to recent reports the membrane based hyaluronic acid synthase (HAS) is at least in part responsible for the attachment of PNNs to the neuronal membrane via binding interactions of PNN constituents such as the lecticans with $\mathrm{HA}[36,74,81]$. A further constituent of the PNNs is the CSPG termed DSD$1-P G /$ phosphacan $[55,66,82-86]$. Phosphacan is a splice variant of the receptor protein tyrosine phosphatase- (RPTP-) $\beta / \zeta$, a transmembrane receptor linked to several relevant signal transduction pathways [43, 87].

Phosphacan interacts with other ECM constituents, namely, the tenascin glycoproteins, which are also compounds of PNNs. The glycoprotein tenascin-R (Tnr) of the tenascin gene family $[48-50,55,88-92]$ is a further prominent component within PNN structures. Tnr has so far exclusively been detected in the CNS where it occurs as a trimeric glycoprotein [90, 92]. Tnr displays binding sites for members of the lectican family, for example, versican [93], brevican [94], and neurocan [95], and has the potential to cross-link ECM components due to its trimeric structure [13].

Link proteins are important for enhancing and maintaining the interactions of CSPGs with HA and involved in the formation of PNNs because thereby they increase the stability of the PNN structure [55, 74] (Figure 1). HAPLN1 (HA and proteoglycan link protein 1)/Crtll (cartilage link protein 1), HAPLN2/Bral1 [96], and HAPLN4/Bral2 (brain link proteins 1 and 2) [97] are the most thoroughly studied link proteins relating to PNNs and are known for their interaction with CSPGs and HA [48, 55, 98-101]. Summarizing these indications, it can be stated that the CSPGs of the lectican family, as well as HA, Tnr, and link proteins, determine the scaffold of PNNs in the central nervous system by establishing intensely structured extracellular aggregates $[28,55,102]$.

Importantly, a number of regulatory molecules are associated with PNNs. These variable elements can be linked to the main components by either direct interaction with core protein or by binding with GAG chains. One example is tenascin-C (Tnc) that is expressed during the development of the central nervous system [86, 103-108]. Also the glycoprotein semaphorin 3A [76,109-111] (see below), which plays a crucial role in the process of axon guidance $[112,113]$, is attached to molecules of PNNs, in particular proteoglycans [114]. Other PNN-associated molecules, in particular matrix 


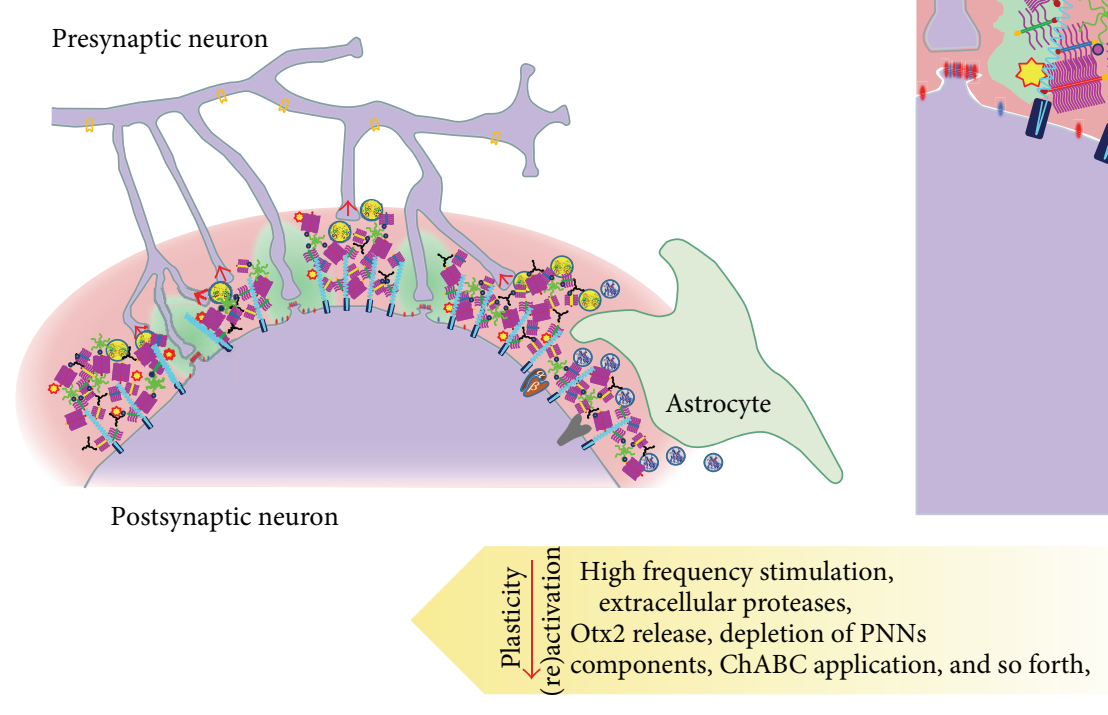

(a)

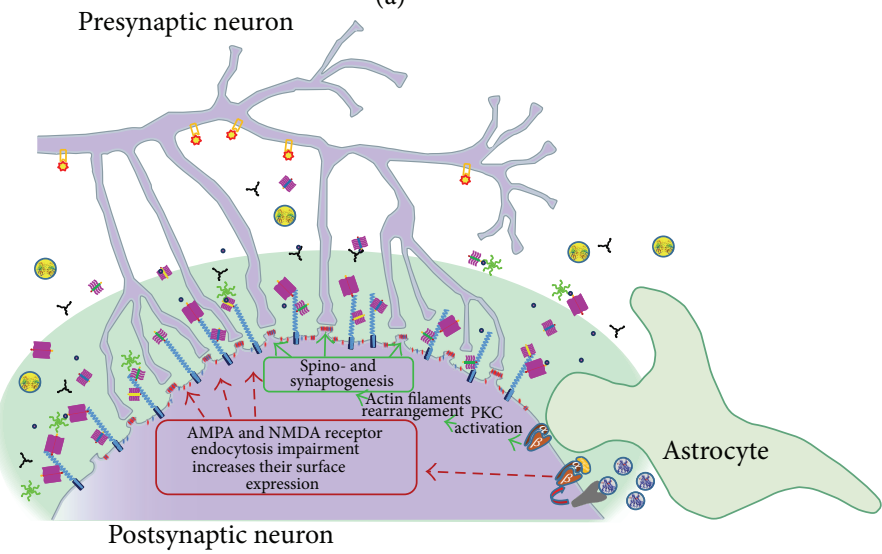

(b)
Y TNR
간 TNC
- Link protein
Semaphorin $3 \mathrm{~A}$
(1). $\mathrm{TNF} \alpha$
\& Growth factor

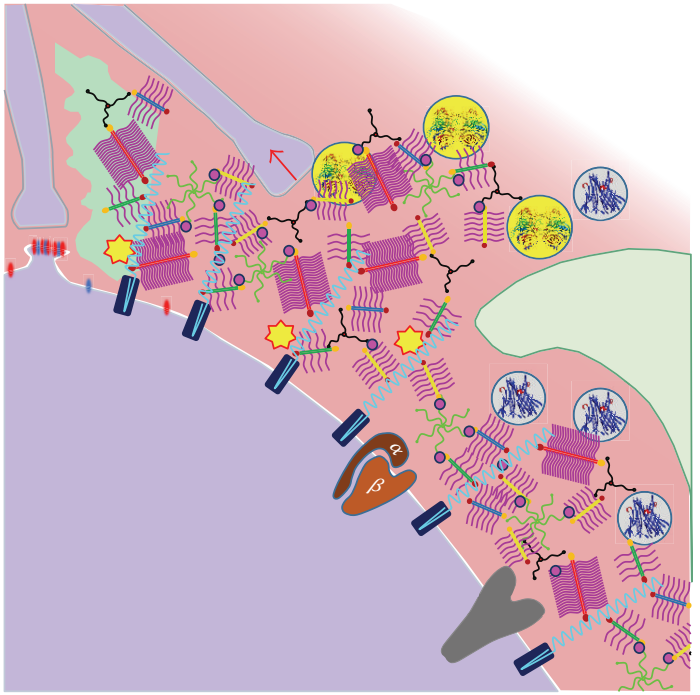

$\left(a^{\prime}\right)$

FIGURE 1: PNNs and neural plasticity. The cartoon depicts the composition of an ECM coat in a PNN on neuronal surfaces, as produced jointly by neurons and astrocytes (a), magnified in $\left(a^{\prime}\right)$. PNNs restrict adult neuronal plasticity, by providing inhibitory environment (depicted in red) restricting astrocyte-induced plasticity and by embedding repulsive guidance molecules. Only several permissive areas are left, indicated in green. Remodelling of PNNs and consequent regain of plasticity (b) can be induced by distinct treatments, as shown by the arrow. 


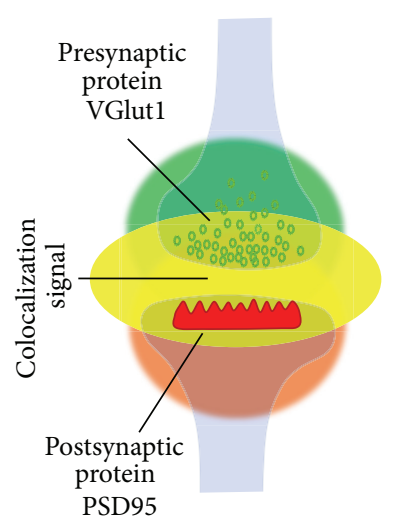

(d)

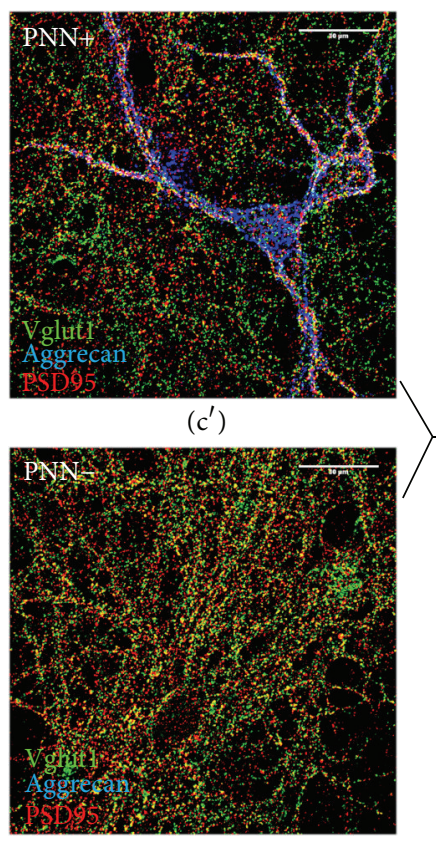

$\left(c^{\prime \prime}\right)$

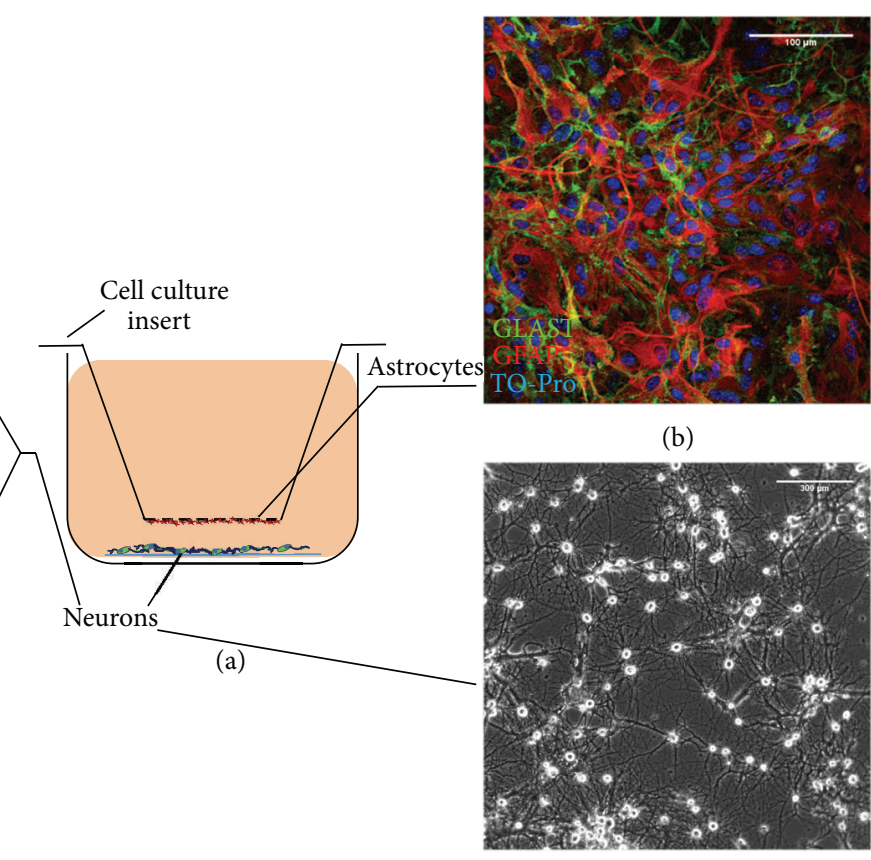

(c)

Figure 2: Neuron-astrocyte coculture for the study of synaptogenesis. A schematic view of the neuron-astrocyte indirect coculture system is presented. (a) Primary embryonic day 15 mouse hippocampal neurons are cultivated on coverslips in the presence of primary cortical astrocytes maintained as monolayers in cell culture inserts (b). Thereby, astrocytes and neurons share the same medium in the absence of membrane-mediated contacts. With the use of this system, neurons can be cultivated for up to 4 weeks and form active neuronal networks (c) in completely defined media [132], suggesting a reliable model for synaptogenesis studies. A subgroup of neurons can develop PNNs, as indicated by a specific marker $\left(c^{\prime}\right.$ and $\left.c^{\prime \prime}\right)$. Presynaptic and postsynaptic terminals can be visualised using immunocytochemical labelling of presynaptic and postsynaptic proteins. The overlap of pre- and postsynaptic puncta indicates the structural synapses (d). Quantification of synaptic puncta using an analysis software permits the quantitative evaluation of synapse formation in vitro under different treatment conditions. For experimental details see $[129,130]$.

metalloproteases (MMPs) and Otx2, also contribute to neural plasticity and will be discussed further in this review.

\section{Astrocyte-ECM-Neuron Interactions in Neuronal Plasticity}

The impact of astrocytes on neuronal networks development, their regulation, and plasticity has been a subject of intensive research throughout the last decades [115]. As the new insights were provided, our understanding of glia has switched from an intercellular "glue" to an active component of the CNS [30, 116-118]. We now know that astrocytes not only provide neuronal networks with essential structural and metabolic support, but also modulate neuronal activity and neural plasticity $[30,69,119-121]$ and support the formation of neuronal circuits [111, 122]. In addition, astrocyte-neuron crosstalk is crucial for neuroprotection and is involved in neurological diseases progression in several cases [119, 120]. According to the current concept of the tripartite synapse astrocytes are necessary for the establishment and regulation of synapses [69, 117, 122-125]. Furthermore, glial subpopulations can also directly form synapses with neurons [126]. Neurons contact astrocytes in multiple ways including ephrin-based interactions [127] and ECM-mediated integrin signalling [128]. ECM molecules mediate a substantial part of astrocyte-neuron interactions and to consider them as independent entity in a conceptual construct that has been termed the tetrapartite synapse has been proposed $[69,119,123]$.

Indirect neuron-astrocyte coculture in vitro models provided a powerful tool to study astrocyte-neuronal interactions. Applying this approach, Pyka et al. $[129,130]$ combined pure cultures of primary embryonic hippocampus neurons with pure cultures of primary astrocytes, using cell culture inserts to avoid direct membrane-mediated cell contacts. Under these conditions neurons survived and developed neuronal networks when sharing the defined culture medium with primary astrocytes (Figure 2). The latter also supported synaptogenesis in the neuronal culture [129]. The use of this coculture system opens the possibility for numerous forms of analysis exclusively for neurons, for example, isolation of mRNA for qRT-PCR, analysis of the transcriptome, expression analysis of distinct proteins via Western Blotting, and immunocytochemistry, while the cells dispose of a long in vitro life span. Furthermore, the unique model allows the investigation of the source of ECM within the shared culture medium. Geissler et al. used an analogous model [131, 132] to reveal the impact of several ECM components on the establishment of neuronal networks and the expression of PNNs [131]. In that approach, neurons and astrocytes were obtained from either wild type or quadruple knockout mice, 
which lack Tnc, Tnr, brevican, and neurocan [133]. Excitatory synapse formation, postsynaptic currents, and PNNs expression were then analysed in different combinations of wild type and knockout cells. Depletion of the four crucial ECM molecules led to an impairment of PNN formation, decreased frequency of miniature inhibitory and excitatory postsynaptic currents, and disturbed synaptogenesis. Indeed, an initial increase of synapse formation after two weeks was followed by the marked decrease of synapse numbers, an effect that was particularly prominent with PNN-bearing neurons, indicating that the latter may be important for synapse stabilization in the long run [131].

Interestingly, the effects of the quadruple knockout were prominent in knockout neurons and could not be rescued by sharing the secretome of wild type astrocytes [131]. As four genes are depleted in the quadruple knockout mouse, it is difficult to attribute the phenotypic changes to one of the missing ECM constituents. Thus, the knockout of neurocan [133] causes only subtle modifications regarding the late phase in long-term potentiation maintenance, without affecting PNNs or brain development [134]. Moreover, the triple knockout of Tnc, Tnr, and versican generates a similar phenotype as the quadruple knockout [133]. Interestingly, neurocan was almost absent in triple knockout mouse brains. Fibulin-1 and fibulin-2 are upregulated and localized interstitially in the quadruple knockout brain, which may exert a compensatory effect by transiting from a tenascin- to a fibulin-cross-linked ECM [133].

\section{PNNs in Neural Plasticity}

A number of regulatory functions of the ECM that is collectively synthesized by neurons and glia are attributed to PNNs (Figure 1). Interestingly, these macromolecular assemblies can modulate different types of neuronal plasticity, including circuit remodelling and synaptic plasticity [73, 80, 135]. During CNS development, neuronal plasticity is required for controlled remodelling of neuronal circuits. At this level, the role of PNNs was abundantly demonstrated in vivo in the context of ocular dominance plasticity (for review see [73]). It has been noted that the expression of molecules forming the PNNs coincides with the closure of the critical period during the development of the brain [73, 80, 135-138]. Increasing evidence also suggests that PNNs are remodelled in correlation with activity $[139,140]$. On the structural level, there is evidence that PNNs restrict neurite growth and the development of synapses [141, 142]. On the synapse level, PNNs compartmentalize the neuronal surface and restrict glutamate receptor mobility [81, 143, 144], thus providing support for synaptic plasticity and stabilizing synapses [37, 142]. Preventing the mobility of AMPA receptors led to a reduction of short-term plasticity in rat primary neurons $[80$, $143,145]$, indicating the possible role of PNNs for memory formation. A number of PNN components were shown to regulate synaptic plasticity in their own right. Neurocan deficiency reduced the stability of late-phase LTP [134], brevican ablation led to significantly impaired LTP [146], and depletion of its binding partner Tnr also caused a reduced
LTP [147]. Interestingly, knockout of the related glycoprotein Tnc led to a complete failure in LTD induction, together with impaired LTP development [148]. It was hypothesized that the consequence of the Tnc-knockout was due to the reduced Ltype VDCC channel signalling.

\subsection{Enzymatic Digestion of PNNs Induces Neural Plastic-} ity. The bacterially derived enzyme chondroitinase $A B C$ (ChABC) has been used in numerous studies for analysing the role of PNNs in neuronal plasticity $[138,149]$. This enzyme degrades especially the GAG chains of CSPGs, more precisely chondroitin-6-sulfate, chondroitin-4-sulfate, dermatan sulfate, and $\mathrm{HA}$ [150], depending on the $\mathrm{pH}$ optimum of the enzyme ( $\mathrm{pH}$ 8.0: chondroitin sulfate; $\mathrm{pH}$ 6.8: $\mathrm{HA}$ ) [151] without altering the core proteins of the ECM. This degradation results in enhanced neuronal plasticity, for example, a higher expression of synaptic proteins in rat hippocampal neurons [130], restoration of ocular dominance plasticity in the adult cat visual cortex $[136,152]$, and enhanced regeneration of sensory projections and corticospinal tract axons within the adult rat spinal cord after lesion $[37,153]$. The inhibitory effects of CSPGs on synapse formation and plasticity could be caused by the chondroitin sulfate GAG (CS-GAG) chains with varying degree of epimerization and sulfation that might result in functional subdomains along the polymer. These domains could interact with and thereby expose a wide range of protein ligands, including the inhibitory semaphorins (see below) $[154,155]$. Alternatively, they can also directly activate specific receptors (for review see [156]) that mediate growth cone stalling or retraction, for example, RPTP $\sigma$ [157]. In spinal cord lesions, the modulation of RPTP $\sigma$ promotes recovery after spinal cord injury [158].

5.2. PNNs Restrict Integrin Signalling. Apart from the compartmentalization of the neuronal surface PNNs also control synaptogenesis through integrin signalling. Astrocytes can make contacts with neurons via integrin receptors. Focal integrin activation further leads to global PKC activation, resulting in excitatory synaptogenesis facilitation [21, 128, 159]. Interestingly, CSPGs that are abundantly expressed in PNNs inhibit integrin activation [36, 47]. Moreover, there is an evidence for direct interaction between CS-GAGs and integrins, for example, the interaction of the integrin $\alpha_{4} \beta_{1}$ and the melanoma chondroitin sulfate proteoglycan $[160$, 161]. A number of alternative ways of how CSPGs may reduce integrin activation have been suggested [162]. From this point of view, modulating the CSPG coating provides another ECM-mediated mechanism of astrocyte-dependent control over neuronal synaptogenesis $[69,130]$.

5.3. PNNs-Associated Molecules and Neural Plasticity. Beyond integrin signalling, PNNs can mediate molecular signals between neurons and astrocytes via a number of regulatory molecules that they capture. A number of growth modulating ligands interact with CS-GAGs, including PTN, FGF, and EGF isoforms [43, 154, 155, 163]. Further ligands include TNF $\alpha$ [164], BDNF, semaphorins [165], and extracellular matrix proteases [164]. Semaphorins are particularly 
interesting because members of this gene family, notably semaphorin $3 \mathrm{~A}$ which is synthesized by both neurons and astrocytes, are growth cone collapse inducing molecules with a strong impact on axon growth and guidance [109, $114,166]$, axon regeneration [110], establishment of neuronal polarity [112], and the development of dendritic spines [167]. Semaphorin 3A can synergize with CSPGs to regulate neuronal migration [168] and abounds in PNNs [114, 165, 169]. There, it binds to chondroitin sulfate E GAGs (CSE-GAGs), a disulfated disaccharide epitope (GlcUA-GalNAc(4S,6S)), also named E unit [169-171], and could contribute to the repulsion of synaptic sprouts and inhibition of synaptogenesis $[37,113]$. Release of semaphorin $3 \mathrm{~A}$ by ChABC could reduce the inhibitory properties of PNNs and thus may explain increased synaptogenesis upon ChABC treatment $[69,130]$.

Along these lines, several of the discovered CSPG-ligands are known to modulate synaptic plasticity and are released from astrocytes. For example, TNF $\alpha$ is involved in astrocytemediated synaptic scaling [172]. In response to the absence of presynaptic potential astrocytes release TNF $\alpha$, which leads to elevated expression of $\beta 3$-integrins at the postsynaptic site. Integrins further enhance AMPARs surface expression through RAP1 inhibition, which leads to the upscaling of postsynaptic currents $[6,172,173]$. ECM proteases, including MMPs, ADAMTS, and TPA, often show a similar mode of action, although their substrates differ. They exhibit elevated expression after LTP induction and support memory formation and learning. Extracellular proteases are not mainly responsible for ECM degradation but rather regulate neural plasticity through cleaving signalling motifs and active forms of growth factors. The reader is welcome to address a recent review for further information [174]. Remarkably, the metallopeptidases Adamts8, Adamts15, and neprilysin are expressed in fast spiking parvalbumin interneurons that are surrounded by PNNs. It is an intriguing possibility that these proteases may partake in PNN remodelling, in dependence of neuronal activity affecting their release [175].

Another intriguing PNN-associated molecule that regulates neural plasticity is Otx2 [176, 177]. This homeoboxcontaining protein is involved in transient reopening of the visual plasticity period in amblyopic mice [178]. When an arginine-lysine doublet peptide is infused, Otx2-localization to PV-containing interneurons is disrupted, PNNs expression is decreased, and neuronal plasticity is reopened in adult mice, comparable to the situation after ChABC treatment $[176,177]$. These results clearly speak in favour of a control of plasticity by interneuronal Otx2 transfer [179-181].

5.4. PNNs and Ionic Homeostasis. The polyanionic nature of PNNs introduces them as an important element of an neuronal excitability regulatory system $[67,68]$. While astrocytes actively remove $\mathrm{K}^{+}$and neurotransmitters from the extracellular space, preventing overexcitation $[119,182]$, PNNs buffer cations in close proximity to neuronal membrane, thus enabling rapid spiking $[139,183,184]$. Together with the fact that PNNs are often found around fast depolarizing Kv3.1b channel expressing interneurons, this observation clearly indicates the potential of this macromolecular buffer for the regulation of inhibition by the interneurons. Moreover, being highly hydrated polyanions some compounds of PNNs are needed to maintain brain extracellular space [67]. In particular, reduction of hyaluronic acid synthesis upon HAS knockout led to severe brain extracellular space reduction, diffusion impairment, and epileptiform activity [185].

To summarize, astrocyte-ECM-neuron interaction provide, to our current knowledge, four main groups of mechanisms to modulate neural plasticity: (i) compartmentalization of neuronal surface to restrict and to stabilize synapse formation; (ii) synaptogenesis restriction through integrin signalling suppression; (iii) mediation of molecular guidance signals for synaptogenesis and synaptic plasticity; (iv) ionic gradients and extracellular space maintenance. All these mechanisms are crucial for CNS development, function, and homeostasis. It is no surprise that malfunctioning of this three-party orchestra can cause multiple neurological diseases, which will be addressed in a later paragraph (see below).

\section{Cellular Origins of PNNs Components}

The assumed functions of PNNs raise the question about which cellular compartments contribute to their construction. In the realm of the tripartite synapse both astrocytes and neurons could be the source of secreted ECM building blocks of the PNNs (Figure 2). This poses questions relating to their relative roles and the regulatory mechanisms involved in these distinct cellular compartments. To understand how the interplay between glia, neurons, and PNNs affects neuronal plasticity, it is necessary to identify the cellular sources of PNNs components. So far, only few researchers addressed this question $[49,51,55]$. For this reason, we will review the available data about the expression of PNNs components by astrocytes and neurons under physiological conditions (Table 1).

Miyata et al. first showed [51] that cultured neurons can express PNNs in the absence of astrocytes. Using pure cultures of rat cortical neurons, they found the presence of WFA lectin labelled PNNs around parvalbumin-containing interneurons. These PNNs also contained neurocan, phosphacan $[85,87]$, neuroglycan C, and HA. The expression of PNNs increased as the neurons maturated, matching the timelines of their development in vivo. Importantly, under these experimental conditions, WFA labelling surrounded synapsin puncta in immunofluorescence stained preparations. This evidence indicates that the development of structurally integral PNNs does not depend on astrocytes.

Further, Carulli et al. [55] addressed the question of cellular sources of PNN components in rat cerebellum. The authors combined immunohistochemistry with in situ hybridization to determine which cell types express mRNAs encoding a variety of proteins contributing to PNNs formation. Briefly, neurocan, aggrecan, and link proteins Crtll and Bral2 were expressed by neurons, not glial cells. Versican and phosphacan mRNA localized to NG2 glia and oligodendrocytes but was absent in neurons. Brevican mRNA was found in neurons and astrocytes, while Tnr was expressed by NG2 glia, oligodendrocytes, and neurons. It is interesting to note that link proteins Crtll and Bral2, originating from neurons, are crucial for PNNs structural integrity $[74,186]$. 
TABLE 1: Cellular sources of the major PNNs components.

\begin{tabular}{|c|c|c|c|c|c|c|c|c|c|}
\hline \multirow{2}{*}{ Name } & \multicolumn{2}{|c|}{ Neurons } & \multicolumn{2}{|c|}{ Astrocytes } & \multicolumn{2}{|c|}{ Oligodendrocytes } & \multicolumn{2}{|c|}{ NG2 glia } & \multirow{2}{*}{ Citations } \\
\hline & In vitro & In vivo & In vitro & In vivo & In vitro & In vivo & In vitro & In vivo & \\
\hline HA & ++ & ++ & ++ & ++ & - & - & - & - & {$[49,55,74-76]$} \\
\hline Aggrecan & ++ & ++ & ++ & - & - & - & - & - & {$[46-51]$} \\
\hline Brevican & - & $+{ }^{1}$ & +++ & +++ & - & - & - & - & [55-57] \\
\hline Neurocan & +++ & +++ & $t^{2}$ & - & - & - & - & - & {$[46,55,60,61]$} \\
\hline Phosphacan & - & ++ & - & ++ & - & ++ & - & ++ & {$[55,82,83]$} \\
\hline Versican & $t^{3}$ & - & $t^{3}$ & - & +++ & +++ & - & ++ & {$[46,55,63]$} \\
\hline Tnr & ++ & ++ & $+^{4}$ & - & ++ & ++ & - & ++ & {$[48-50,55,88,89]$} \\
\hline Tnc & - & $t^{5}$ & +++ & +++ & - & - & - & - & [103-106] \\
\hline Crtll & - & +++ & - & - & - & - & - & - & {$[48,55,98]$} \\
\hline Bral2 & - & +++ & - & - & - & - & - & - & {$[48,55,98]$} \\
\hline Semaphorin 3A & - & ++ & ++ & ++ & - & - & - & - & {$[76,109-111]$} \\
\hline
\end{tabular}

Symbol +++ indicates the evidence for strong protein and/or mRNA expression, almost restricted to a certain cell type; symbol ++ indicates moderate expression under physiological conditions; + indicates weak or transient expression in a particular cellular subtype or under certain experimental conditions, indicated by superscript footnotes and described below. Dashes indicate the absence of evidence for cell type specific expression published so far.

${ }^{1}$ Neurons of molecular layer of cerebellar cortex and by large excitatory deep cerebellar nuclei neurons [55].

${ }^{2}$ Astrocytic monolayers in culture [61].

${ }^{3}$ Neurons and astrocytes differentiated from embryonic stem cells [46].

${ }^{4}$ Type 2 but not type 1 astrocytes [89].

${ }^{5}$ Transient expression by neurons of spinal cord and hippocampus during development [103, 105].

In the absence of one of these two proteins, PNNs are attenuated and neuronal plasticity is enhanced $[98,187]$.

Addressing this issue, Giamanco and Matthews [49] have carefully addressed the question of cellular sources of PNNs components. Applying $\mathrm{AraC}$ and $\mathrm{KCl}$ in different combinations to mixed cultures of mouse cortical glia and neurons, the authors dissected neuronal and glial contributions to PNNs formation. Briefly, Tnr, neurocan, versican, phosphacan, brevican, Crtl1, Bral2, and HAPLN3 appeared to be expressed in a glia-dependent manner, whereas aggrecan expression was neuron-dependent. Interestingly, HAsynthesis was both neuron- and glia-dependent. However, these data do not rule out that glia-dependent components can be produced by neurons. Although only a limited number of articles focused on the study of cellular origins of PNNs components, accessory information can be drawn from a number of other studies. A thorough search in literature databases targeting the expression of major PNNs compounds in different types of cells of the mammalian CNS under physiological conditions provided further insight. We have further verified whether the cellular origin of a component of our interest was clearly stated. The results of our search are summarized in Table 1.

Summarizing the available reports, both neurons and glial cells can produce the majority of PNNs components, while neurocan and link proteins Crtll and Bral2 seem to be neuron-specific, at least in vivo and under physiological conditions. It is important to note, however, that the expression profile of PNNs components may change upon activation of glia or under conditions of neuronal hyperactivity. For instance, when glial activation occurs upon brain injury or experimental stress conditions, astrocytes start to express sustainable levels of neurocan [61, 188-190], and phosphacan expression is highly upregulated in reactive astrocytes [82, $189,191,192]$.

\section{Neurologic Diseases and PNN Formation}

Several neurologic diseases have been identified to exhibit an impaired PNN formation in vitro and in vivo, including epilepsy and schizophrenia (for detailed review see [145]). As a consequence of the fact that PNN formation and maintenance underlie alterations in these diseases, neuronal plasticity is also affected, which, for example, is the case in epilepsy. Here, the disease is accompanied by epileptic seizures triggered by an altered GABAergic signalling [193] together with an abnormal expression and functionality of GABA receptor seen in primary dentate granule cells in a temporal lobe epilepsy rat model [194-196]. A compromised signalling capacity of GABAergic neurons could also be found in a rat model of Alzheimer's disease, in which rats were treated with amyloid beta [197]. Moreover, animal models regarding the psychiatric disease schizophrenia demonstrate an alteration of the inhibition of GABA together with a loss of parvalbumin-expressing neurons [198-200]. As emphasized previously, PNNs enwrap GABAergic neurons [24, 26, 67].

In addition, several PNN components display a modified expression in animal models mimicking epilepsy and schizophrenia, which is consistent with a change of neuronal plasticity. Different expression patterns of neurocan and phosphacan were observed in the hippocampus in a temporal lobe epileptic rat model compared to healthy control rats [201]. Another study also showed an impairment of neurocan and phosphacan, as well as Tnc, using a different mouse model of epilepsy, in which domoate, a specific glutamate 
agonist, is injected next to the hippocampus in vivo [202]. Here, immunohistochemical staining revealed a significantly higher expression of neurocan and Tnc seven days after injection, whereas the expression of phosphacan was not increased until 14 days after the injection [202]. Reports in the literature suggest that neurocan expression within hippocampal regions is increased in parallel with a decreased phosphacan expression, followed by the death of pyramidal cells after kainic acid application in rats [203]. PNN formation during schizophrenia is altered in that PNN densities, as revealed by immunohistochemical staining of human postmortem brains with WFA, are highly diminished in the prefrontal cortex of schizophrenic patients [204]. The importance of the existence of a healthy composition of PNNs is shown in another study analysing human postmortem brains of patients suffering from schizophrenia by immunohistochemistry. There, the authors found a higher number of glial cells positive for CSPGs in the amygdala and the entorhinal cortex, but also a decreased density of PNNs in parts of the amygdala and the entorhinal cortex [72]. A continuative study of this group could recently examine a reduction of glial cells positive for aggrecan in the schizophrenic amygdala [205].

These findings contrast the composition of PNNs in the brain of Alzheimer's disease patients. Recently, a study uncovered that PNNs in postmortem brains were unaffected, in particular with regard to the expression of brevican, aggrecan, Tnr, and Crtll, whereas HA displayed an enhanced expression in amyloid beta plaque areas [206]. In light of these findings, the authors suggested that PNNs might exert a neuroprotective function for the neurons of Alzheimer's disease patients. In future, a substantial effort will be required to unravel the relations between altered PNN formation and neurological diseases in order to gain insight into useful therapeutic strategies.

\section{Conflict of Interests}

The authors declare that they have no conflict of interests.

\section{Acknowledgments}

We acknowledge grant support by the Stem Cell Network North Rhine-Westphalia, the German Research Foundation (DFG: SFB 509; SFB 642; SPP 1109; SPP-1172, Fa 159/11-1,2,3; Fa 159/16-1; GRK 736; GSC 98/1; SPP-1757, Fa 159/20-1), the Mercur-Foundation (Mercator Research Center Ruhr, Grant Pr-2011-0010), the German Ministry of Education, Research and Technology (BMBF 01GN0503), and the Ruhr-University (President's special programme call 2008).

\section{References}

[1] D. Choquet and A. Triller, "The role of receptor diffusion in the organization of the postsynaptic membrane," Nature Reviews Neuroscience, vol. 4, no. 4, pp. 251-265, 2003.

[2] C. C. Garner, R. G. Zhai, E. D. Gundelfinger, and N. E. Ziv, "Molecular mechanisms of CNS synaptogenesis," Trends in Neurosciences, vol. 25, no. 5, pp. 243-250, 2002.
[3] J. R. Sanes and J. W. Lichtman, "Induction, assembly, maturation and maintenance of a postsynaptic apparatus," Nature Reviews Neuroscience, vol. 2, no. 11, pp. 791-805, 2001.

[4] P. Scheiffele, "Cell-cell signaling during synapse formation in the CNS," Annual Review of Neuroscience, vol. 26, pp. 485-508, 2003.

[5] M. B. Dalva, A. C. McClelland, and M. S. Kayser, "Cell adhesion molecules: signalling functions at the synapse," Nature Reviews Neuroscience, vol. 8, no. 3, pp. 206-220, 2007.

[6] E. C. Beattie, D. Stellwagen, W. Morishita et al., "Control of synaptic strength by glial TNF $\alpha$," Science, vol. 295, no. 5563, pp. 2282-2285, 2002.

[7] A. Contractor, C. Rogers, C. Maron, M. Henkemeyer, G. T. Swanson, and S. F. Heinemann, "Trans-synaptic Eph receptorephrin signaling in hippocampal mossy fiber LTP," Science, vol. 296, no. 5574, pp. 1864-1869, 2002.

[8] T. Biederer, Y. Sara, M. Mozhayeva et al., "SynCAM, a synaptic adhesion molecule that drives synapse assembly," Science, vol. 297, no. 5586, pp. 1525-1531, 2002.

[9] H. Tanaka, W. Shan, G. R. Phillips et al., "Molecular modification of N-cadherin in response to synaptic activity," Neuron, vol. 25, no. 1, pp. 93-107, 2000.

[10] M. Yamagata, J. R. Sanes, and J. A. Weiner, "Synaptic adhesion molecules," Current Opinion in Cell Biology, vol. 15, no. 5, pp. 621-632, 2003.

[11] M. Yamagata, J. A. Weiner, and J. R. Sanes, "Sidekicks: synaptic adhesion molecules that promote lamina-specific connectivity in the retina," Cell, vol. 110, no. 5, pp. 649-660, 2002.

[12] A. M. Craig and Y. Kang, "Neurexin-neuroligin signaling in synapse development," Current Opinion in Neurobiology, vol. 17, no. 1, pp. 43-52, 2007.

[13] A. Dityatev and M. Schachner, "Extracellular matrix molecules and synaptic plasticity," Nature Reviews Neuroscience, vol. 4, no. 6, pp. 456-468, 2003.

[14] B. L. Patton, J. M. Cunningham, J. Thyboll et al., "Properly formed but improperly localized synaptic specializations in the absence of laminin $\alpha 4$," Nature Neuroscience, vol. 4, no. 6, pp. 597-604, 2001.

[15] P. Chavis and G. Westbrook, "Integrins mediate functional preand postsynaptic maturation at a hippocampal synapse," Nature, vol. 411, no. 6835 , pp. 317-321, 2001.

[16] H. Umemori, M. W. Linhoff, D. M. Ornitz, and J. R. Sanes, "FGF22 and its close relatives are presynaptic organizing molecules in the mammalian brain," Cell, vol. 118, no. 2, pp. 257-270, 2004.

[17] S. E. Craven and D. S. Bredt, "PDZ proteins organize synaptic signaling pathways," Cell, vol. 93, no. 4, pp. 495-498, 1998.

[18] A. E.-D. El-Husseini, E. Schnell, D. M. Chetkovich, R. A. Nicoll, and D. S. Bredt, "PSD-95 involvement in maturation of excitatory synapses,” Science, vol. 290, no. 5495, pp. 1364-1368, 2000.

[19] K. Shen and C. W. Cowan, "Guidance molecules in synapse formation and plasticity," Cold Spring Harbor Perspectives in Biology, vol. 2, no. 4, Article ID a001842, 2010.

[20] A. Naba, K. R. Clauser, S. Hoersch, H. Liu, S. A. Carr, and R. O. Hynes, "The matrisome: in silico definition and in vivo characterization by proteomics of normal and tumor extracellular matrices," Molecular \& Cellular Proteomics, vol. 11, no. 4, Article ID M111.014647, 2012.

[21] R. O. Hynes and A. Naba, "Overview of the matrisome-an inventory of extracellular matrix constituents and functions," 
Cold Spring Harbor perspectives in biology, vol. 4, no. 1, Article ID a004903, 2012.

[22] M. R. Celio, R. Spreafico, S. De Biasi, and L. Vitellaro-Zuccarello, "Perineuronal nets: past and present," Trends in Neurosciences, vol. 21, no. 12, pp. 510-515, 1998.

[23] G. Bruckner, G. Seeger, K. Brauer, W. Hartig, J. Kacza, and V. Bigl, "Cortical areas are revealed by distribution patterns of proteoglycan components and parvalbumin in the Mongolian gerbil and rat," Brain Research, vol. 658, no. 1-2, pp. 67-86, 1994.

[24] W. Hartig, K. Brauer, and G. Bruckner, "Wisteria floribunda agglutinin-labelled nets surround parvalbumin-containing neurons," NeuroReport, vol. 3, no. 10, pp. 869-872, 1992.

[25] D. Hausen, G. Brückner, M. Drlicek, W. Härtig, K. Brauer, and V. Bigl, "Pyramidal cells ensheathed by perineuronal nets in human motor and somatosensory cortex," NeuroReport, vol. 7, no. 11, pp. 1725-1729, 1996.

[26] F. Wegner, W. Härtig, A. Bringmann et al., "Diffuse perineuronal nets and modified pyramidal cells immunoreactive for glutamate and the $\operatorname{GABA}(\mathrm{A})$ receptor alphal subunit form a unique entity in rat cerebral cortex," Experimental Neurology, vol. 184, no. 2, pp. 705-714, 2003.

[27] M. R. Celio and I. Blümcke, "Perineuronal nets-a specialized form of extracellular matrix in the adult nervous system," Brain Research Reviews, vol. 19, no. 1, pp. 128-145, 1994.

[28] S. S. Deepa, D. Carulli, C. Galtrey et al., "Composition of perineuronal net extracellular matrix in rat brain: a different disaccharide composition for the net-associated proteoglycans," Journal of Biological Chemistry, vol. 281, no. 26, pp. 17789-17800, 2006.

[29] H. Pantazopoulos, N. Lange, L. Hassinger, and S. Berretta, "Subpopulations of neurons expressing parvalbumin in the human amygdala," Journal of Comparative Neurology, vol. 496, no. 5, pp. 706-722, 2006.

[30] A. Volterra and J. Meldolesi, "Astrocytes, from brain glue to communication elements: the revolution continues," Nature Reviews Neuroscience, vol. 6, no. 8, pp. 626-640, 2005.

[31] U. Theocharidis, K. Long, C. ffrench-Constant, and A. Faissner, "Regulation of the neural stem cell compartment by extracellular matrix constituents," Progress in Brain Research, vol. 214, pp. 3-28, 2014.

[32] A. Faissner and J. Reinhard, "The extracellular matrix compartment of neural stem and glial progenitor cells," Glia, vol. 63, no. 8, pp. 1330-1349, 2015.

[33] C. S. Barros, S. J. Franco, and U. Müller, "Extracellular matrix: functions in the nervous system," Cold Spring Harbor Perspectives in Biology, vol. 3, no. 1, Article ID a005108, 2011.

[34] J. Reinhard, S. C. Joachim, and A. Faissner, "Extracellular matrix remodeling during retinal development," Experimental Eye Research, vol. 133, pp. 132-140, 2015.

[35] M. T. Fitch and J. Silver, "CNS injury, glial scars, and inflammation: inhibitory extracellular matrices and regeneration failure," Experimental Neurology, vol. 209, no. 2, pp. 294-301, 2008.

[36] J. C. F. Kwok, G. Dick, D. Wang, and J. W. Fawcett, "Extracellular matrix and perineuronal nets in CNS repair," Developmental Neurobiology, vol. 71, no. 11, pp. 1073-1089, 2011.

[37] J. W. Fawcett, "The extracellular matrix in plasticity and regeneration after CNS injury and neurodegenerative disease," Progress in Brain Research, vol. 218, pp. 213-226, 2015.

[38] A. Faissner, "The tenascin gene family in axon growth and guidance," Cell and Tissue Research, vol. 290, no. 2, pp. 331-341, 1997.
[39] Y. Yamaguchi, "Heparan sulfate proteoglycans in the nervous system: their diverse roles in neurogenesis, axon guidance, and synaptogenesis," Seminars in Cell and Developmental Biology, vol. 12, no. 2, pp. 99-106, 2001.

[40] Y. Yamaguchi, M. Inatani, Y. Matsumoto, J. Ogawa, and F. Irie, "Roles of heparan sulfate in mammalian brain development: current views based on the findings from Extl conditional knockout studies," Progress in Molecular Biology and Translational Science, vol. 93, pp. 133-152, 2010.

[41] A. Xiong, S. Kundu, and K. Forsberg-Nilsson, "Heparan sulfate in the regulation of neural differentiation and glioma development," The FEBS Journal, vol. 281, no. 22, pp. 4993-5008, 2014.

[42] S. Sarrazin, W. C. Lamanna, and J. D. Esko, "Heparan sulfate proteoglycans," Cold Spring Harbor Perspectives in Biology, vol. 3, no. 7, Article ID a004952, 33 pages, 2011.

[43] N. Maeda, "Proteoglycans and neuronal migration in the cerebral cortex during development and disease," Frontiers in Neuroscience, vol. 9, article 98, 2015.

[44] R. V. Iozzo and L. Schaefer, "Proteoglycan form and function: a comprehensive nomenclature of proteoglycans," Matrix Biology, vol. 42, pp. 11-55, 2015.

[45] C. E. Bandtlow and D. R. Zimmermann, "Proteoglycans in the developing brain: new conceptual insights for old proteins," Physiological Reviews, vol. 80, no. 4, pp. 1267-1290, 2000.

[46] M. Abaskharoun, M. Bellemare, E. Lau, and R. U. Margolis, "Expression of hyaluronan and the hyaluronan-binding proteoglycans neurocan, aggrecan, and versican by neural stem cells and neural cells derived from embryonic stem cells," Brain Research, vol. 1327, pp. 6-15, 2010.

[47] F. T. Afshari, J. C. Kwok, L. White, and J. W. Fawcett, "Schwann cell migration is integrin-dependent and inhibited by astrocyteproduced aggrecan," Glia, vol. 58, no. 7, pp. 857-869, 2010.

[48] C. M. Galtrey, J. C. F. Kwok, D. Carulli, K. E. Rhodes, and J. W. Fawcett, "Distribution and synthesis of extracellular matrix proteoglycans, hyaluronan, link proteins and tenascin- $\mathrm{R}$ in the rat spinal cord," European Journal of Neuroscience, vol. 27, no. 6, pp. 1373-1390, 2008.

[49] K. A. Giamanco and R. T. Matthews, "Deconstructing the perineuronal net: cellular contributions and molecular composition of the neuronal extracellular matrix," Neuroscience, vol. 218, pp. 367-384, 2012.

[50] K. A. Giamanco, M. Morawski, and R. T. Matthews, "Perineuronal net formation and structure in aggrecan knockout mice," Neuroscience, vol. 170, no. 4, pp. 1314-1327, 2010.

[51] S. Miyata, Y. Nishimura, N. Hayashi, and A. Oohira, "Construction of perineuronal net-like structure by cortical neurons in culture," Neuroscience, vol. 136, no. 1, pp. 95-104, 2005.

[52] K. Doege, M. Sasaki, and Y. Yamada, "Rat and human cartilage proteoglycan (aggrecan) gene structure," Biochemical Society Transactions, vol. 18, no. 2, pp. 200-202, 1990.

[53] K. Doege, M. Sasaki, E. Horigan, J. R. Hassell, and Y. Yamada, "Complete primary structure of the rat cartilage proteoglycan core protein deduced from cDNA clones," The Journal of Biological Chemistry, vol. 262, no. 36, pp. 17757-17767, 1987.

[54] M. Morawski, G. Brückner, T. Arendt, and R. T. Matthews, "Aggrecan: beyond cartilage and into the brain," International Journal of Biochemistry and Cell Biology, vol. 44, no. 5, pp. 690693, 2012.

[55] D. Carulli, K. E. Rhodes, D. J. Brown et al., "Composition of perineuronal nets in the adult rat cerebellum and the cellular origin of their components," Journal of Comparative Neurology, vol. 494, no. 4, pp. 559-577, 2006. 
[56] M. G. Hamel, J. Mayer, and P. E. Gottschall, "Altered production and proteolytic processing of brevican by transforming growth factor $\beta$ in cultured astrocytes," Journal of Neurochemistry, vol. 93, no. 6, pp. 1533-1541, 2005.

[57] H. Yamada, K. Watanabe, M. Shimonaka, and Y. Yamaguchi, "Molecular cloning of brevican, a novel brain proteoglycan of the aggrecan/versican family," The Journal of Biological Chemistry, vol. 269, no. 13, pp. 10119-10126, 1994.

[58] U. Rauch, H. Meyer, C. Brakebusch et al., "Sequence and chromosomal localization of the mouse brevican gene," Genomics, vol. 44, no. 1, pp. 15-21, 1997.

[59] C. I. Seidenbecher, K. Richter, U. Rauch, R. Fassler, C. C. Garner, and E. D. Gundelfinger, "Brevican, a chondroitin sulfate proteoglycan of rat brain, occurs as secreted and cell surface glycosylphosphatidylinositol-anchored isoforms," Journal of Biological Chemistry, vol. 270, no. 45, pp. 27206-27212, 1995.

[60] R. K. Margolis, U. W. E. Rauch, P. Maurel, and R. U. Margolis, "Neurocan and phosphacan: two major nervous tissue-specific chondroitin sulfate proteoglycans," Perspectives on Developmental Neurobiology, vol. 3, no. 4, pp. 273-290, 1996.

[61] R. A. Asher, D. A. Morgenstern, P. S. Fidler et al., "Neurocan is upregulated in injured brain and in cytokine-treated astrocytes," Journal of Neuroscience, vol. 20, no. 7, pp. 2427-2438, 2000.

[62] U. Rauch, L. Karthikeyan, P. Maurel, R. U. Margolis, and R. K. Margolis, "Cloning and primary structure of neurocan, a developmentally regulated, aggregating chondroitin sulfate proteoglycan of brain," The Journal of Biological Chemistry, vol. 267, no. 27, pp. 19536-19547, 1992.

[63] R. A. Asher, D. A. Morgenstern, M. C. Shearer, K. H. Adcock, P. Pesheva, and J. W. Fawcett, "Versican is upregulated in CNS injury and is a product of oligodendrocyte lineage cells," The Journal of Neuroscience, vol. 22, no. 6, pp. 2225-2236, 2002.

[64] D. R. Zimmermann and E. Ruoslahti, "Multiple domains of the large fibroblast proteoglycan, versican," EMBO Journal, vol. 8, no. 10, pp. 2975-2981, 1989.

[65] Y. Yamaguchi, "Lecticans: organizers of the brain extracellular matrix," Cellular and Molecular Life Sciences, vol. 57, no. 2, pp. 276-289, 2000.

[66] D. R. Zimmermann and M. T. Dours-Zimmermann, "Extracellular matrix of the central nervous system: from neglect to challenge," Histochemistry and Cell Biology, vol. 130, no. 4, pp. 635-653, 2008.

[67] G. Brückner, K. Brauer, W. Härtig et al., "Perineuronal nets provide a polyanionic, glia-associated form of microenvironment around certain neurons in many parts of the rat brain.," Glia, vol. 8, no. 3, pp. 183-200, 1993.

[68] M. Morawski, M. K. Brückner, P. Riederer, G. Brückner, and T. Arendt, "Perineuronal nets potentially protect against oxidative stress," Experimental Neurology, vol. 188, no. 2, pp. 309-315, 2004.

[69] A. Faissner, M. Pyka, M. Geissler et al., "Contributions of astrocytes to synapse formation and maturation-potential functions of the perisynaptic extracellular matrix," Brain Research Reviews, vol. 63, no. 1-2, pp. 26-38, 2010.

[70] H. Hilbig, H.-J. Bidmon, U. Blohm, and K. Zilles, "Wisteria floribunda agglutinin labeling patterns in the human cortex: a tool for revealing areal borders and subdivisions in parallel with immunocytochemistry," Anatomy and Embryology, vol. 203, no. 1, pp. 45-52, 2001.

[71] E. Schmidt, T. P. Wolski, and R. J. Kulesza, "Distribution of perineuronal nets in the human superior olivary complex," Hearing Research, vol. 265, no. 1-2, pp. 15-24, 2010.
[72] H. Pantazopoulos, T.-U. W. Woo, M. P. Lim, N. Lange, and S. Berretta, "Extracellular matrix-glial abnormalities in the amygdala and entorhinal cortex of subjects diagnosed with schizophrenia," Archives of General Psychiatry, vol. 67, no. 2, pp. 155-166, 2010.

[73] D. Wang and J. Fawcett, "The perineuronal net and the control of CNS plasticity," Cell and Tissue Research, vol. 349, no. 1, pp. 147-160, 2012.

[74] J. C. F. Kwok, D. Carulli, and J. W. Fawcett, "In vitro modeling of perineuronal nets: hyaluronan synthase and link protein are necessary for their formation and integrity," Journal of Neurochemistry, vol. 114, no. 5, pp. 1447-1459, 2010.

[75] R. Cargill, S. G. Kohama, J. Struve et al., "Astrocytes in aged nonhuman primate brain gray matter synthesize excess hyaluronan," Neurobiology of Aging, vol. 33, no. 4, pp. 830.e13830.e24, 2012.

[76] S. Marret, B. Delpech, A. Delpech et al., "Expression and effects of hyaluronan and of the hyaluronan-binding protein hyaluronectin in newborn rat brain glial cell cultures," Journal of Neurochemistry, vol. 62, no. 4, pp. 1285-1295, 1994.

[77] K. Meyer, A. Linker, and M. M. Rapport, "The production of monosaccharides from hyaluronic acid by beta-glucuronidase," The Journal of Biological Chemistry, vol. 192, no. 1, pp. 275-281, 1951.

[78] B. P. Toole, "Hyaluronan is not just a goo!", The Journal of Clinical Investigation, vol. 106, no. 3, pp. 335-336, 2000.

[79] E. Ruoslahti, "Structure and biology of proteoglycans," Annual Review of Cell Biology, vol. 4, pp. 229-255, 1988.

[80] R. Frischknecht and E. D. Gundelfinger, "The brain's extracellular matrix and its role in synaptic plasticity," Advances in Experimental Medicine and Biology, vol. 970, pp. 153-171, 2012.

[81] R. Frischknecht and C. I. Seidenbecher, "The crosstalk of hyaluronan-based extracellular matrix and synapses," Neuron Glia Biology, vol. 4, no. 3, pp. 249-257, 2008.

[82] A. Dobbertin, K. E. Rhodes, J. Garwood et al., "Regulation of RPTP $\beta$ /phosphacan expression and glycosaminoglycan epitopes in injured brain and cytokine-treated glia," Molecular and Cellular Neuroscience, vol. 24, no. 4, pp. 951-971, 2003.

[83] S. E. Snyder, J. Li, P. E. Schauwecker, T. H. McNeill, and S. R. Salton, "Comparison of RPTP zeta/beta, phosphacan, and trkB mRNA expression in the developing and adult rat nervous system and induction of RPTP zeta/beta and phosphacan mRNA following brain injury," Molecular Brain Research, vol. 40, no. 1, pp. 76-96, 1996.

[84] A. Faissner, A. Clement, A. Lochter, A. Streit, C. Mandl, and M. Schachner, "Isolation of a neural chondroitin sulfate proteoglycan with neurite outgrowth promoting properties," Journal of Cell Biology, vol. 126, no. 3, pp. 783-799, 1994.

[85] J. Garwood, O. Schnädelbach, A. Clement, K. Schütte, A. Bach, and A. Faissner, "DSD-1-proteoglycan is the mouse homolog of phosphacan and displays opposing effects on neurite outgrowth dependent on neuronal lineage," Journal of Neuroscience, vol. 19, no. 10, pp. 3888-3899, 1999.

[86] E. S. Wintergerst, A. Faissner, and M. R. Celio, “The proteoglycan DSD-1-PG occurs in perineuronal nets around parvalbumin-immunoreactive interneurons of the rat cerebral cortex," International Journal of Developmental Neuroscience, vol. 14, no. 3, pp. 249-255, 1996.

[87] J. Garwood, F. Rigato, N. Heck, and A. Faissner, "Tenascin glycoproteins and the complementary ligand DSD-1-PG/phosphacan-structuring the neural extracellular matrix during 
development and repair," Restorative Neurology and Neuroscience, vol. 19, no. 1-2, pp. 51-64, 2001.

[88] R. Probstmeier, C. C. Stichel, H. W. Müller, H. Asou, and P. Pesheva, "Chondroitin sulfates expressed on oligodendrocytederived Tenascin- $\mathrm{R}$ are involved in neural cell recognition. Functional implications during CNS development and regeneration," Journal of Neuroscience Research, vol. 60, no. 1, pp. 21-36, 2000.

[89] U. Bartsch, P. Pesheva, M. Raff, and M. Schachner, "Expression of janusin (J1-160/180) in the retina and optic nerve of the developing and adult mouse," Glia, vol. 9, no. 1, pp. 57-69, 1993.

[90] R. Chiquet-Ehrismann and M. Chiquet, "Tenascins: regulation and putative functions during pathological stress," Journal of Pathology, vol. 200, no. 4, pp. 488-499, 2003.

[91] R. Chiquet-Ehrismann and R. P. Tucker, "Tenascins and the importance of adhesion modulation," Cold Spring Harbor perspectives in biology, vol. 3, no. 5, 2011.

[92] A. Joester and A. Faissner, "The structure and function of tenascins in the nervous system," Matrix Biology, vol. 20, no. 1, pp. 13-22, 2001.

[93] A. Aspberg, C. Binkert, and E. Ruoslahti, "The versican Ctype lectin domain recognizes the adhesion protein tenascinR," Proceedings of the National Academy of Sciences of the United States of America, vol. 92, no. 23, pp. 10590-10594, 1995.

[94] A. Aspberg, R. Miura, S. Bourdoulous et al., "The C-type lectin domains of lecticans, a family of aggregating chondroitin sulfate proteoglycans, bind tenascin-R by protein-protein interactions independent of carbohydrate moiety," Proceedings of the National Academy of Sciences of the United States of America, vol. 94, no. 19, pp. 10116-10121, 1997.

[95] P. Milev, A. Chiba, M. Häring et al., "High affinity binding and overlapping localization of neurocan and phosphacan/proteintyrosine phosphatase- $\zeta / \beta$ with tenascin- $\mathrm{R}$, amphoterin, and the heparin-binding gowth-associated molecule," The Journal of Biological Chemistry, vol. 273, no. 12, pp. 6998-7005, 1998.

[96] S. Hirakawa, T. Oohashi, W.-D. Su et al., "The brain link protein-1 (BRAL1): cDNA cloning, genomic structure, and characterization as a novel link protein expressed in adult brain," Biochemical and Biophysical Research Communications, vol. 276, no. 3, pp. 982-989, 2000.

[97] Y. Bekku, W.-D. Su, S. Hirakawa et al., "Molecular cloning of Bral2, a novel brain-specific link protein, and immunohistochemical colocalization with brevican in perineuronal nets," Molecular and Cellular Neuroscience, vol. 24, no. 1, pp. 148-159, 2003.

[98] D. Carulli, T. Pizzorusso, J. C. F. Kwok et al., "Animals lacking link protein have attenuated perineuronal nets and persistent plasticity," Brain, vol. 133, no. 8, pp. 2331-2347, 2010.

[99] F. Binette, J. Cravens, B. Kahoussi, D. R. Haudenschild, and P. F. Goetinck, "Link protein is ubiquitously expressed in noncartilaginous tissues where it enhances and stabilizes the interaction of proteoglycans with hyaluronic acid," Journal of Biological Chemistry, vol. 269, no. 29, pp. 19116-19122, 1994.

[100] U. Rauch, S. Hirakawa, T. Oohashi, J. Kappler, and G. Roos, "Cartilage link protein interacts with neurocan, which shows hyaluronan binding characteristics different from CD44 and TSG-6," Matrix Biology, vol. 22, no. 8, pp. 629-639, 2004.

[101] A. P. Spicer, A. Joo, and R. A. Bowling Jr., "A hyaluronan binding link protein gene family whose members are physically linked adjacent to chrondroitin sulfate proteoglycan core protein genes. The missing links," The Journal of Biological Chemistry, vol. 278, no. 23, pp. 21083-21091, 2003.
[102] D. Cabulli, K. E. Rhodes, and J. W. Fawcett, "Upregulation of aggrecan, link protein 1, and hyaluronan synthases during formation of perineuronal nets in the rat cerebellum," Journal of Comparative Neurology, vol. 501, no. 1, pp. 83-94, 2007.

[103] Y. Zhang, P. N. Anderson, G. Campbell, H. Mohajeri, M. Schachner, and A. R. Lieberman, "Tenascin-C expression by neurons and glial cells in the rat spinal cord: changes during postnatal development and after dorsal root or sciatic nerve injury," Journal of Neurocytology, vol. 24, no. 8, pp. 585-601, 1995.

[104] S. Siddiqui, A. Horvat-Bröcker, and A. Faissner, "The gliaderived extracellular matrix glycoprotein tenascin-C promotes embryonic and postnatal retina axon outgrowth via the alternatively spliced fibronectin type III domain TNfnD," Neuron Glia Biology, vol. 4, no. 4, pp. 271-283, 2008.

[105] L. Ferhat, N. Chevassus Au Louis, I. Jorquera et al., "Transient increase of tenascin- $\mathrm{C}$ in immature hippocampus: astroglial and neuronal expression," Journal of Neurocytology, vol. 25, no. 1, pp. 53-66, 1996.

[106] S. Siddiqui, A. Horvat-Broecker, and A. Faissner, "Comparative screening of glial cell types reveals extracellular matrix that inhibits retinal axon growth in a chondroitinase $\mathrm{ABC}$-resistant fashion," Glia, vol. 57, no. 13, pp. 1420-1438, 2009.

[107] T. Czopka, A. Von Holst, G. Schmidt, C. Ffrench-Constant, and A. Faissner, "Tenascin $\mathrm{C}$ and tenascin $\mathrm{R}$ similarly prevent the formation of myelin membranes in a RhoA-dependent manner, but antagonistically regulate the expression of myelin basic protein via a separate pathway," Glia, vol. 57, no. 16, pp. 17901801, 2009.

[108] E. Garcion, A. Halilagic, A. Faissner, and C. Ffrench-Constant, "Generation of an environmental niche for neural stem cell development by the extracellular matrix molecule tenascin C," Development, vol. 131, no. 14, pp. 3423-3432, 2004.

[109] R. J. Giger, R. J. Pasterkamp, S. Heijnen, A. J. G. D. Holtmaat, and J. Verhaagen, "Anatomical distribution of the chemorepellent semaphorin III/collapsin- 1 in the adult rat and human brain: predominant expression in structures of the olfactoryhippocampal pathway and the motor system," Journal of Neuroscience Research, vol. 52, no. 1, pp. 27-42, 1998.

[110] M. Hashimoto, H. Ino, M. Koda et al., "Regulation of semaphorin $3 \mathrm{~A}$ expression in neurons of the rat spinal cord and cerebral cortex after transection injury," Acta Neuropathologica, vol. 107, no. 3, pp. 250-256, 2004.

[111] A. V. Molofsky, K. W. Kelley, H.-H. Tsai et al., "Astrocyteencoded positional cues maintain sensorimotor circuit integrity," Nature, vol. 509, no. 7499, pp. 189-194, 2014.

[112] M. Shelly, L. Cancedda, B. K. Lim et al., "Semaphorin3A regulates neuronal polarization by suppressing axon formation and promoting dendrite growth," Neuron, vol. 71, no. 3, pp. 433446, 2011.

[113] E. Koropouli and A. L. Kolodkin, "Semaphorins and the dynamic regulation of synapse assembly, refinement, and function," Current Opinion in Neurobiology, vol. 27, pp. 1-7, 2014.

[114] J. De Wit, F. De Winter, J. Klooster, and J. Verhaagen, "Semaphorin $3 \mathrm{~A}$ displays a punctate distribution on the surface of neuronal cells and interacts with proteoglycans in the extracellular matrix," Molecular and Cellular Neuroscience, vol. 29, no. 1, pp. $40-55,2005$.

[115] E. M. Ullian, K. S. Christopherson, and B. A. Barres, "Role for glia in synaptogenesis," Glia, vol. 47, no. 3, pp. 209-216, 2004.

[116] N. J. Allen and B. A. Barres, "Neuroscience: glia-more than just brain glue," Nature, vol. 457, no. 7230, pp. 675-677, 2009. 
[117] A. Araque, G. Carmignoto, and P. G. Haydon, "Dynamic signaling between astrocytes and neurons," Annual Review of Physiology, vol. 63, pp. 795-813, 2001.

[118] P. G. Haydon, "Glia: listening and talking to the synapse," Nature Reviews Neuroscience, vol. 2, no. 3, pp. 185-193, 2001.

[119] G. E. Barreto, J. Gonzalez, Y. Torres, and L. Morales, "Astrocyticneuronal crosstalk: implications for neuroprotection from brain injury," Neuroscience Research, vol. 71, no. 2, pp. 107-113, 2011.

[120] A. V. Gourine and S. Kasparov, "Astrocytes as brain interoceptors," Experimental Physiology, vol. 96, no. 4, pp. 411-416, 2011.

[121] C. R. Figley and P. W. Stroman, "The role(s) of astrocytes and astrocyte activity in neurometabolism, neurovascular coupling, and the production of functional neuroimaging signals," European Journal of Neuroscience, vol. 33, no. 4, pp. 577-588, 2011.

[122] L. E. Clarke and B. A. Barres, "Emerging roles of astrocytes in neural circuit development," Nature Reviews Neuroscience, vol. 14, no. 5, pp. 311-321, 2013.

[123] A. Dityatev and D. A. Rusakov, "Molecular signals of plasticity at the tetrapartite synapse," Current Opinion in Neurobiology, vol. 21, no. 2, pp. 353-359, 2011.

[124] M. R. Freeman, “Glial control of synaptogenesis," Cell, vol. 120, no. 3, pp. 292-293, 2005.

[125] G. Perea, M. Navarrete, and A. Araque, "Tripartite synapses: astrocytes process and control synaptic information," Trends in Neurosciences, vol. 32, no. 8, pp. 421-431, 2009.

[126] D. E. Bergles, R. Jabs, and C. Steinhäuser, "Neuron-glia synapses in the brain," Brain Research Reviews, vol. 63, no. 1-2, pp. 130-137, 2010.

[127] A. Filosa, S. Paixo, S. D. Honsek et al., "Neuron-glia communication via EphA4/ephrin-A3 modulates LTP through glial glutamate transport," Nature Neuroscience, vol. 12, no. 10, pp. 1285-1292, 2009.

[128] H. Hama, C. Hara, K. Yamaguchi, and A. Miyawaki, "PKC signaling mediates global enhancement of excitatory synaptogenesis in neurons triggered by local contact with astrocytes," Neuron, vol. 41, no. 3, pp. 405-415, 2004.

[129] M. Pyka, C. Busse, C. Seidenbecher, E. D. Gundelfinger, and A. Faissner, "Astrocytes are crucial for survival and maturation of embryonic hippocampal neurons in a neuron-glia cell-insert coculture assay," Synapse, vol. 65, no. 1, pp. 41-53, 2011.

[130] M. Pyka, C. Wetzel, A. Aguado, M. Geissler, H. Hatt, and A. Faissner, "Chondroitin sulfate proteoglycans regulate astrocytedependent synaptogenesis and modulate synaptic activity in primary embryonic hippocampal neurons," European Journal of Neuroscience, vol. 33, no. 12, pp. 2187-2202, 2011.

[131] M. Geissler, C. Gottschling, A. Aguado et al., "Primary hippocampal neurons, which lack four crucial extracellular matrix molecules, display abnormalities of synaptic structure and function and severe deficits in perineuronal net formation," The Journal of Neuroscience, vol. 33, no. 18, pp. 7742-7755, 2013.

[132] M. Geissler and A. Faissner, "A new indirect co-culture set up of mouse hippocampal neurons and cortical astrocytes on microelectrode arrays," Journal of Neuroscience Methods, vol. 204, no. 2, pp. 262-272, 2012.

[133] U. Rauch, X.-H. Zhou, and G. Roos, "Extracellular matrix alterations in brains lacking four of its components," Biochemical and Biophysical Research Communications, vol. 328, no. 2, pp. 608617, 2005.

[134] X.-H. Zhou, C. Brakebusch, H. Matthies et al., "Neurocan is dispensable for brain development," Molecular and Cellular Biology, vol. 21, no. 17, pp. 5970-5978, 2001.
[135] M. Sonntag, M. Blosa, S. Schmidt, R. Rübsamen, and M. Morawski, "Perineuronal nets in the auditory system," Hearing Research, 2015.

[136] T. Pizzorusso, P. Medini, N. Berardi, S. Chierzi, J. W. Fawcett, and L. Maffei, "Reactivation of ocular dominance plasticity in the adult visual cortex," Science, vol. 298, no. 5596, pp. 12481251, 2002.

[137] N. Gogolla, P. Caroni, A. Lüthi, and C. Herry, "Perineuronal nets protect fear memories from erasure," Science, vol. 325, no. 5945, pp. 1258-1261, 2009.

[138] N. Berardi, T. Pizzorusso, and L. Maffei, "Extracellular matrix and visual cortical plasticity: freeing the synapse," Neuron, vol. 44, no. 6, pp. 905-908, 2004.

[139] A. Dityatev, G. Brückner, G. Dityateva, J. Grosche, R. Kleene, and M. Schachner, "Activity-dependent formation and functions of chondroitin sulfate-rich extracellular matrix of perineuronal nets," Developmental Neurobiology, vol. 67, no. 5, pp. 570588, 2007.

[140] C. C. Smith, R. Mauricio, L. Nobre et al., "Differential regulation of perineuronal nets in the brain and spinal cord with exercise training," Brain Research Bulletin, vol. 111, pp. 20-26, 2015.

[141] R. J. McKeon, R. C. Schreiber, J. S. Rudge, and J. Silver, "Reduction of neurite outgrowth in a model of glial scarring following CNS injury is correlated with the expression of inhibitory molecules on reactive astrocytes," Journal of Neuroscience, vol. 11, no. 11, pp. 3398-3411, 1991.

[142] M. Karetko and J. Skangiel-Kramska, "Diverse functions of perineuronal nets," Acta Neurobiologiae Experimentalis, vol. 69, no. 4, pp. 564-577, 2009.

[143] R. Frischknecht, M. Heine, D. Perrais, C. I. Seidenbecher, D. Choquet, and E. D. Gundelfinger, "Brain extracellular matrix affects AMPA receptor lateral mobility and short-term synaptic plasticity," Nature Neuroscience, vol. 12, no. 7, pp. 897-904, 2009.

[144] A. Dityatev, C. I. Seidenbecher, and M. Schachner, "Compartmentalization from the outside: the extracellular matrix and functional microdomains in the brain," Trends in Neurosciences, vol. 33, no. 11, pp. 503-512, 2010.

[145] S. Soleman, M. A. Filippov, A. Dityatev, and J. W. Fawcett, "Targeting the neural extracellular matrix in neurological disorders," Neuroscience, vol. 253, pp. 194-213, 2013.

[146] C. Brakebusch, C. I. Seidenbecher, F. Asztely et al., "Brevicandeficient mice display impaired hippocampal CA1 long-term potentiation but show no obvious deficits in learning and memory," Molecular and Cellular Biology, vol. 22, no. 21, pp. 7417-7427, 2002.

[147] O. Bukalo, M. Schachner, and A. Dityatev, "Modification of extracellular matrix by enzymatic removal of chondroitin sulfate and by lack of tenascin-R differentially affects several forms of synaptic plasticity in the hippocampus," Neuroscience, vol. 104, no. 2, pp. 359-369, 2001.

[148] M. R. Evers, B. Salmen, O. Bukalo et al., "Impairment of Ltype $\mathrm{Ca}^{2+}$ channel-dependent forms of hippocampal synaptic plasticity in mice deficient in the extracellular matrix glycoprotein tenascin-C," The Journal of Neuroscience, vol. 22, no. 16, pp. 7177-7194, 2002.

[149] L. E. Dansie and I. M. Ethell, "Casting a net on dendritic spines: the extracellular matrix and its receptors," Developmental Neurobiology, vol. 71, no. 11, pp. 956-981, 2011.

[150] V. Prabhakar, R. Raman, I. Capila, C. J. Bosques, K. Pojasek, and R. Sasisekharan, "Biochemical characterization of the chondroitinase ABC I active site," Biochemical Journal, vol. 390, no. 2, pp. 395-405, 2005. 
[151] T. Yamagata, H. Saito, O. Habuchi, and S. Suzuki, "Purification and properties of bacterial chondroitinases and chondrosulfatases," The Journal of Biological Chemistry, vol. 243, no. 7, pp. 1523-1535, 1968.

[152] V. Vorobyov, J. C. F. Kwok, J. W. Fawcett, and F. Sengpiel, "Effects of digesting chondroitin sulfate proteoglycans on plasticity in cat primary visual cortex," Journal of Neuroscience, vol. 33, no. 1, pp. 234-243, 2013.

[153] E. J. Bradbury, L. D. F. Moon, R. J. Popat et al., "Chondroitinase $\mathrm{ABC}$ promotes functional recovery after spinal cord injury," Nature, vol. 416, no. 6881, pp. 636-640, 2002.

[154] A. Purushothaman, K. Sugaharas, and A. Faissner, "Chondroitin sulfate 'wobble motifs' modulate maintenance and differentiation of neural stem cells and their progeny," Journal of Biological Chemistry, vol. 287, no. 5, pp. 2935-2942, 2012.

[155] K. Sugahara and T. Mikami, "Chondroitin/dermatan sulfate in the central nervous system," Current Opinion in Structural Biology, vol. 17, no. 5, pp. 536-545, 2007.

[156] K. Kadomatsu and K. Sakamoto, "Mechanisms of axon regeneration and its inhibition: roles of sulfated glycans," Archives of Biochemistry and Biophysics, vol. 558, pp. 36-41, 2014.

[157] Y. Shen, A. P. Tenney, S. A. Busch et al., "PTP $\sigma$ is a receptor for chondroitin sulfate proteoglycan, an inhibitor of neural regeneration," Science, vol. 326, no. 5952, pp. 592-596, 2009.

[158] B. T. Lang, J. M. Cregg, M. A. DePaul et al., "Modulation of the proteoglycan receptor PTPsigma promotes recovery after spinal cord injury," Nature, vol. 518, no. 7539, pp. 404-408, 2014.

[159] K. Pozo, L. A. Cingolani, S. Bassani, F. Laurent, M. Passafaro, and Y. Goda, " $\beta 3$ integrin interacts directly with GluA2 AMPA receptor subunit and regulates AMPA receptor expression in hippocampal neurons," Proceedings of the National Academy of Sciences of the United States of America, vol. 109, no. 4, pp. 13231328, 2012.

[160] J. Iida, A. M. L. Meijne, T. R. Oegema Jr. et al., "A role of chondroitin sulfate glycosaminoglycan binding site in $\alpha 4 \beta 1$ integrin-mediated melanoma cell adhesion," The Journal of Biological Chemistry, vol. 273, no. 10, pp. 5955-5962, 1998.

[161] J. Yang, M. A. Price, C. L. Neudauer et al., "Melanoma chondroitin sulfate proteoglycan enhances FAK and ERK activation by distinct mechanisms," The Journal of Cell Biology, vol. 165, no. 6, pp. 881-891, 2004.

[162] N. J. Gardiner, "Integrins and the extracellular matrix: key mediators of development and regeneration of the sensory nervous system," Developmental Neurobiology, vol. 71, no. 11, pp. 1054-1072, 2011.

[163] S. S. Deepa, Y. Umehara, S. Higashiyama, N. Itoh, and K. Sugahara, "Specific molecular interactions of oversulfated chondroitin sulfate $\mathrm{E}$ with various heparin-binding growth factors. Implications as a physiological binding partner in the brain and other tissues," The Journal of Biological Chemistry, vol. 277, no. 46, pp. 43707-43716, 2002.

[164] D. Crespo, R. A. Asher, R. Lin, K. E. Rhodes, and J. W. Fawcett, "How does chondroitinase promote functional recovery in the damaged CNS?" Experimental Neurology, vol. 206, no. 2, pp. 159-171, 2007.

[165] D. Carulli, S. Foscarin, A. Faralli, E. Pajaj, and F. Rossi, "Modulation of semaphorin $3 \mathrm{~A}$ in perineuronal nets during structural plasticity in the adult cerebellum," Molecular and Cellular Neuroscience, vol. 57, pp. 10-22, 2013.

[166] J. de Wit and J. Verhaagen, "Proteoglycans as modulators of axon guidance cue function," Advances in Experimental Medicine and Biology, vol. 600, pp. 73-89, 2007.
[167] R. J. Pasterkamp and R. J. Giger, "Semaphorin function in neural plasticity and disease," Current Opinion in Neurobiology, vol. 19, no. 3, pp. 263-274, 2009.

[168] G. Zimmer, S. M. Schanuel, S. Bürger et al., "Chondroitin sulfate acts in concert with semaphorin $3 \mathrm{~A}$ to guide tangential migration of cortical interneurons in the ventral telencephalon," Cerebral Cortex, vol. 20, no. 10, pp. 2411-2422, 2010.

[169] T. Vo, D. Carulli, E. M. E. Ehlert et al., "The chemorepulsive axon guidance protein semaphorin $3 \mathrm{~A}$ is a constituent of perineuronal nets in the adult rodent brain," Molecular and Cellular Neuroscience, vol. 56, pp. 186-200, 2013.

[170] K. Sugahara, T. Mikami, T. Uyama, S. Mizuguchi, K. Nomura, and $\mathrm{H}$. Kitagawa, "Recent advances in the structural biology of chondroitin sulfate and dermatan sulfate," Current Opinion in Structural Biology, vol. 13, no. 5, pp. 612-620, 2003.

[171] G. B. Ten Dam, E. M. A. van de Westerlo, A. Purushothaman et al., "Antibody GD3G7 selected against embryonic glycosaminoglycans defines chondroitin sulfate-E domains highly upregulated in ovarian cancer and involved in vascular endothelial growth factor binding," The American Journal of Pathology, vol. 171, no. 4, pp. 1324-1333, 2007.

[172] A. Dityatev, M. Schachner, and P. Sonderegger, "The dual role of the extracellular matrix in synaptic plasticity and homeostasis," Nature Reviews Neuroscience, vol. 11, no. 11, pp. 735-746, 2010.

[173] D. Stellwagen and R. C. Malenka, "Synaptic scaling mediated by glial TNF- $\alpha$," Nature, vol. 440, no. 7087, pp. 1054-1059, 2006.

[174] E. Tsilibary, A. Tzinia, L. Radenovic et al., "Neural ECM proteases in learning and synaptic plasticity," in Progress in Brain Research, B. W.-H. Alexander and D. P. Asla, Eds., vol. 214, chapter 6, pp. 135-157, Elsevier, 2014.

[175] J. Rossier, A. Bernard, J.-H. Cabungcal et al., "Cortical fastspiking parvalbumin interneurons enwrapped in the perineuronal net express the metallopeptidases Adamts8, Adamts15 and Neprilysin," Molecular Psychiatry, vol. 20, no. 2, pp. 154-161, 2015.

[176] M. Beurdeley, J. Spatazza, H. H. C. Lee et al., "Otx2 binding to perineuronal nets persistently regulates plasticity in the mature visual cortex," Journal of Neuroscience, vol. 32, no. 27, pp. 9429 9437, 2012.

[177] S. Miyata, Y. Komatsu, Y. Yoshimura, C. Taya, and H. Kitagawa, "Persistent cortical plasticity by upregulation of chondroitin 6sulfation," Nature Neuroscience, vol. 15, no. 3, pp. 414-422, 2012.

[178] S. Sugiyama, A. A. Di Nardo, S. Aizawa et al., "Experiencedependent transfer of Otx 2 homeoprotein into the visual cortex activates postnatal plasticity," Cell, vol. 134 , no. 3, pp. 508-520, 2008.

[179] C. Bernard, H.-T. Kim, R. Torero Ibad et al., "Graded Otx2 activities demonstrate dose-sensitive eye and retina phenotypes," Human Molecular Genetics, vol. 23, no. 7, pp. 1742-1753, 2014.

[180] J. Spatazza, H. H. C. Lee, A. A. DiNardo et al., "Choroid-plexusderived Otx2 homeoprotein constrains adult cortical plasticity," Cell Reports, vol. 3, no. 6, pp. 1815-1823, 2013.

[181] C. Quininao, A. Prochiantz, and J. Touboul, "Local homeoprotein diffusion can stabilize boundaries generated by graded positional cues," Development, vol. 142, no. 10, pp. 1860-1868, 2015.

[182] M. L. Olsen and H. Sontheimer, "Functional implications for Kir4.1 channels in glial biology: from $\mathrm{K}^{+}$buffering to cell differentiation," Journal of Neurochemistry, vol. 107, no. 3, pp. 589-601, 2008. 
[183] W. Härtig, A. Derouiche, K. Welt et al., "Cortical neurons immunoreactive for the potassium channel Kv3.1b subunit are predominantly surrounded by perineuronal nets presumed as a buffering system for cations," Brain Research, vol. 842, no. 1, pp. 15-29, 1999.

[184] W. Härtig, A. Singer, J. Grosche, K. Brauer, O. P. Ottersen, and G. Brückner, "Perineuronal nets in the rat medial nucleus of the trapezoid body surround neurons immunoreactive for various amino acids, calcium-binding proteins and the potassium channel subunit Kv3.1b," Brain Research, vol. 899, no. 1-2, pp. 123-133, 2001.

[185] A. M. Arranz, K. L. Perkins, F. Irie et al., "Hyaluronan deficiency due to Has3 knock-out causes altered neuronal activity and seizures via reduction in brain extracellular space," Journal of Neuroscience, vol. 34, no. 18, pp. 6164-6176, 2014.

[186] Y. Bekku, M. Saito, M. Moser et al., "Bral2 is indispensable for the proper localization of brevican and the structural integrity of the perineuronal net in the brainstem and cerebellum," Journal of Comparative Neurology, vol. 520, no. 8, pp. 1721-1736, 2012.

[187] C. Romberg, S. Yang, R. Melani et al., "Depletion of perineuronal nets enhances recognition memory and long-term depression in the perirhinal cortex," Journal of Neuroscience, vol. 33, no. 16, pp. 7057-7065, 2013.

[188] G. M. Smith and C. Strunz, "Growth factor and cytokine regulation of chondroitin sulfate proteoglycans by astrocytes," Glia, vol. 52, no. 3, pp. 209-218, 2005.

[189] R. J. McKeon, M. J. Jurynec, and C. R. Buck, "The chondroitin sulfate proteoglycans neurocan and phosphacan are expressed by reactive astrocytes in the chronic CNS glial scar," Journal of Neuroscience, vol. 19, no. 24, pp. 10778-10788, 1999.

[190] S. W. Schwarzacher, M. Vuksic, C. A. Haas, G. J. Burbach, R. S. Sloviter, and T. Deller, "Neuronal hyperactivity induces astrocytic expression of neurocan in the adult rat hippocampus," Glia, vol. 53, no. 7, pp. 704-714, 2006.

[191] A. Faissner, N. Heck, A. Dobbertin, and J. Garwood, "DSD-1proteoglycan/phosphacan and receptor protein tyrosine phosphatase-beta isoforms during development and regeneration of neural tissues," Advances in Experimental Medicine and Biology, vol. 557, pp. 25-53, 2005.

[192] S. Wiese, M. Karus, and A. Faissner, "Astrocytes as a source for extracellular matrix molecules and cytokines," Frontiers in Pharmacology, vol. 3, article 120, 2012.

[193] J. G. Tasker and F. E. Dudek, "Electrophysiology of GABAmediated synaptic transmission and possible roles in epilepsy," Neurochemical Research, vol. 16, no. 3, pp. 251-262, 1991.

[194] A. R. Brooks-Kayal, M. D. Shumate, H. Jin, T. Y. Rikhter, and D. A. Coulter, "Selective changes in single cell $\mathrm{GABA}_{\mathrm{A}}$ receptor subunit expression and function in temporal lobe epilepsy," Nature Medicine, vol. 4, no. 10, pp. 1166-1172, 1998.

[195] A. Rice, A. Rafiq, S. M. Shapiro, E. R. Jakoi, D. A. Coulter, and R. J. Delorenzo, "Long-lasting reduction of inhibitory function and $\gamma$-aminobutyric acid type A receptor subunit mRNA expression in a model of temporal lobe epilepsy," Proceedings of the National Academy of Sciences of the United States of America, vol. 93, no. 18, pp. 9665-9669, 1996.

[196] N. Zhang, W. Wei, I. Mody, and C. R. Houser, "Altered localization of $\mathrm{GABA}(\mathrm{A})$ receptor subunits on dentate granule cell dendrites influences tonic and phasic inhibition in a mouse model of epilepsy," The Journal of Neuroscience, vol. 27, no. 28, pp. 7520-7531, 2007.
[197] V. Villette, F. Poindessous-Jazat, A. Simon et al., "Decreased rhythmic GABAergic septal activity and memory-associated theta oscillations after hippocampal amyloid-beta pathology in the rat," Journal of Neuroscience, vol. 30, no. 33, pp. 10991-11003, 2010.

[198] A. Y. Wang, K. M. Lohmann, C. K. Yang et al., "Bipolar disorder type 1 and schizophrenia are accompanied by decreased density of parvalbumin- and somatostatin-positive interneurons in the parahippocampal region," Acta Neuropathologica, vol. 122, no. 5, pp. 615-626, 2011.

[199] S. Berretta, "Extracellular matrix abnormalities in schizophrenia," Neuropharmacology, vol. 62, no. 3, pp. 1584-1597, 2012.

[200] C. L. Beasley and G. P. Reynolds, "Parvalbumin-immunoreactive neurons are reduced in the prefrontal cortex of schizophrenics," Schizophrenia Research, vol. 24, no. 3, pp. 349-355, 1997.

[201] S. Kurazono, M. Okamoto, J. Sakiyama et al., "Expression of brain specific chondroitin sulfate proteoglycans, neurocan and phosphacan, in the developing and adult hippocampus of Ihara's epileptic rats," Brain Research, vol. 898, no. 1, pp. 36-48, 2001.

[202] N. Heck, J. Garwood, J.-P. Loeffler, Y. Larmet, and A. Faissner, "Differential upregulation of extracellular matrix molecules associated with the appearance of granule cell dispersion and mossy fiber sprouting during epileptogenesis in a murine model of temporal lobe epilepsy," Neuroscience, vol. 129, no. 2, pp. 309324, 2004.

[203] M. Okamoto, J. Sakiyama, S. Mori et al., "Kainic acid-induced convulsions cause prolonged changes in the chondroitin sulfate proteoglycans neurocan and phosphacan in the limbic structures," Experimental Neurology, vol. 184, no. 1, pp. 179-195, 2003.

[204] S. A. Mauney, K. M. Athanas, H. Pantazopoulos et al., "Developmental pattern of perineuronal nets in the human prefrontal cortex and their deficit in schizophrenia," Biological Psychiatry, vol. 74, no. 6, pp. 427-435, 2013.

[205] H. Pantazopoulos, M. Markota, F. Jaquet et al., "Aggrecan and chondroitin-6-sulfate abnormalities in schizophrenia and bipolar disorder: a postmortem study on the amygdala," Translational Psychiatry, vol. 5, article e496, 2015.

[206] M. Morawski, G. Brückner, C. Jäger, G. Seeger, R. T. Matthews, and T. Arendt, "Involvement of perineuronal and perisynaptic extracellular matrix in Alzheimer's disease neuropathology," Brain Pathology, vol. 22, no. 4, pp. 547-561, 2012. 

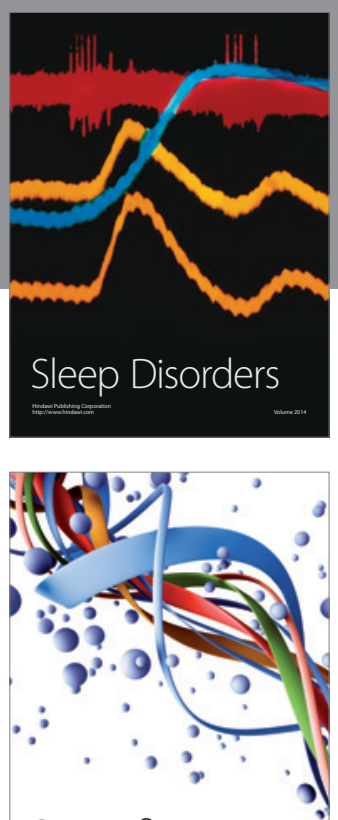

Scientifica
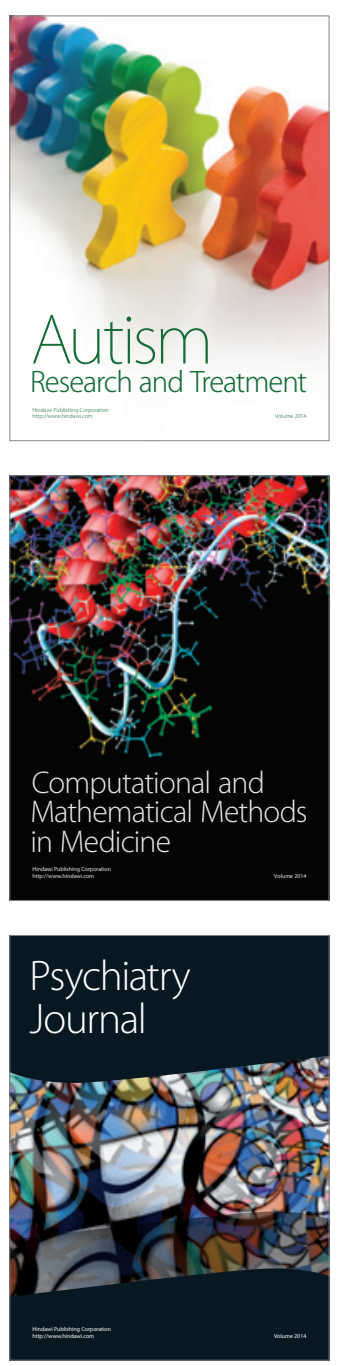
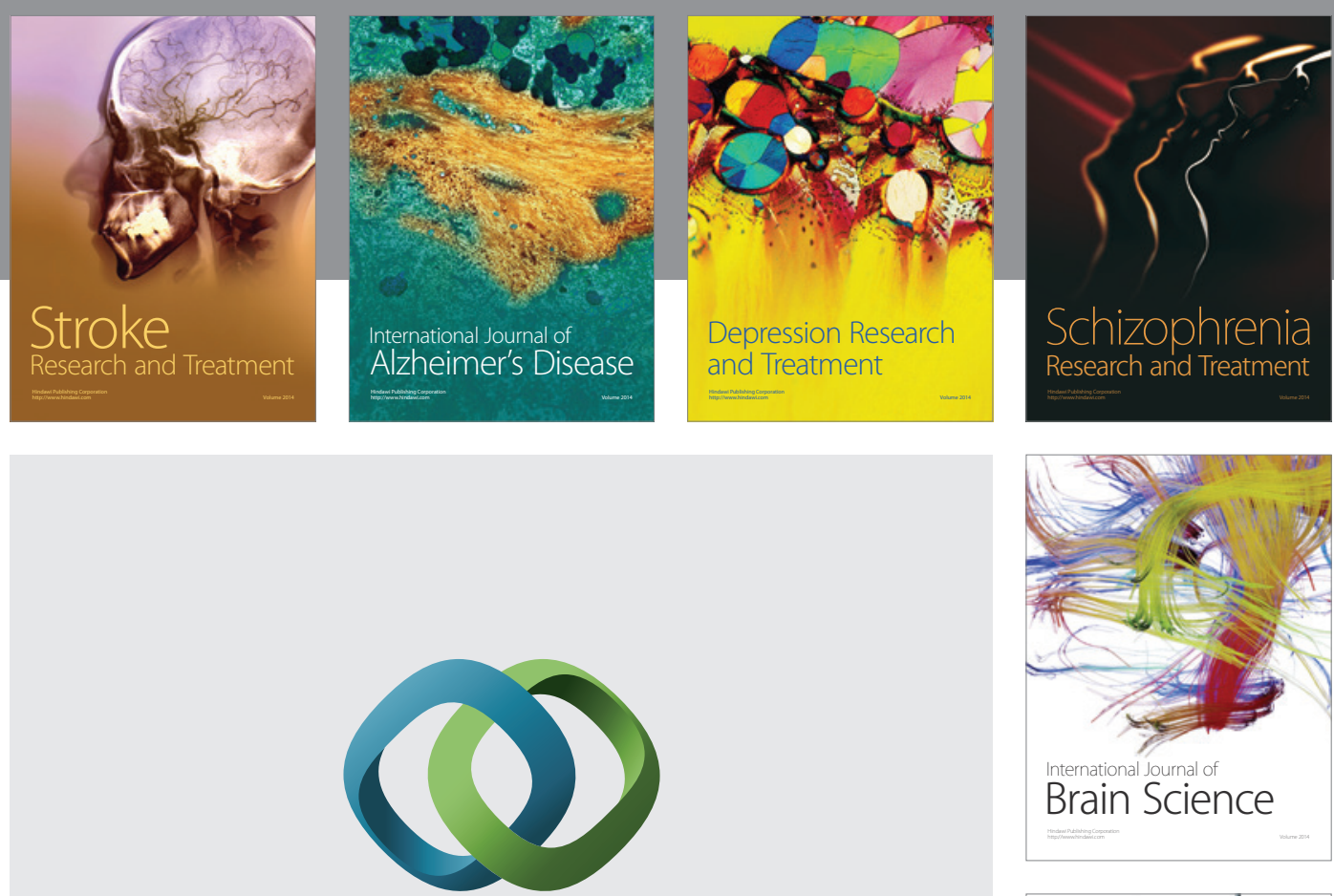

\section{Hindawi}

Submit your manuscripts at

http://www.hindawi.com
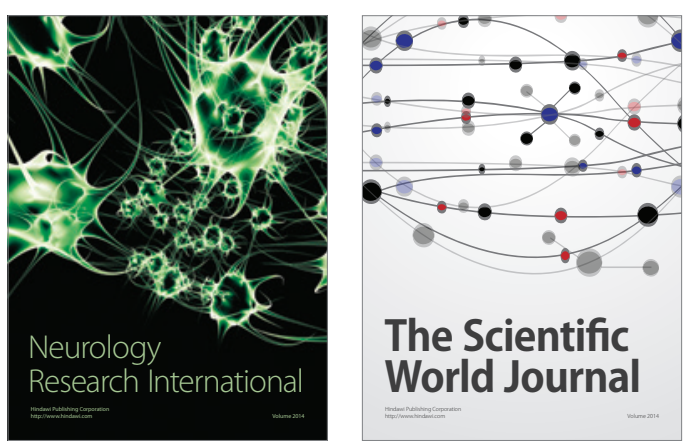

The Scientific World Journal

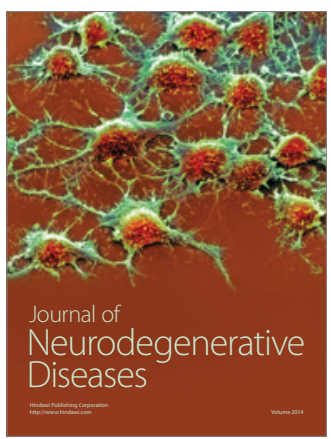

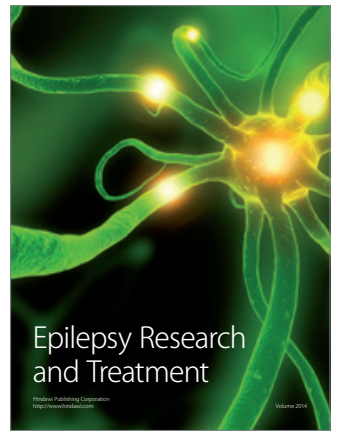

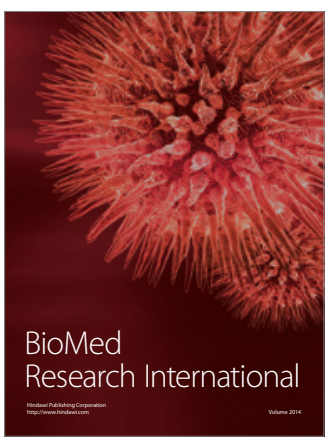

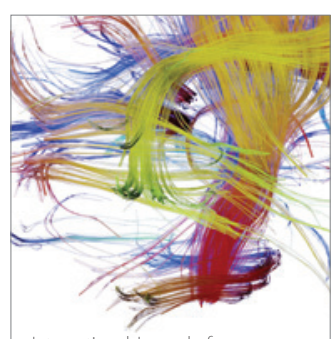

Brain Science

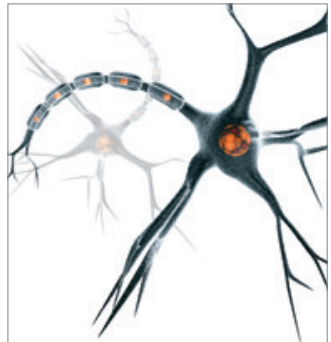

Neural Plasticity
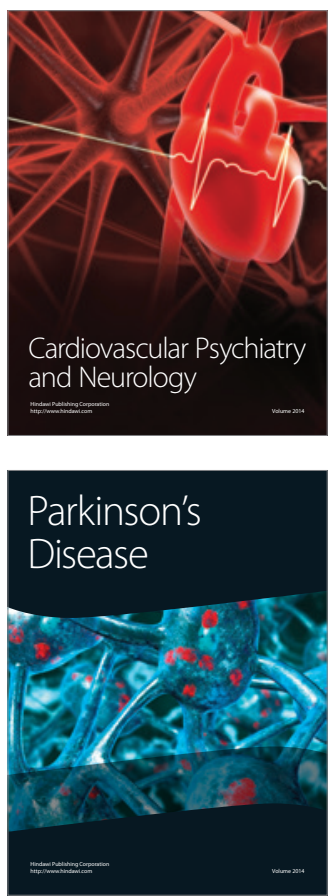